\title{
REDEFINING RESILIENCY AND RESISTANCE
}

Redefining Resiliency, Resistance, and Oppression: A Case Study of the Bahá'í Underground University in Iran

by

Kimiya Tahirih Missaghi

A thesis submitted to the Faculty of Graduate and Postdoctoral Affairs in partial fulfillment of the requirements for the degree of

Master of Arts

in

Legal Studies

Carleton University
Ottawa, Ontario

(C) 2021, Kimiya Tahirih Missaghi 


\begin{abstract}
With over 300,000 followers, Iran's Bahá'í community is the country's largest religious minority and has been systematically marginalized and oppressed since its founding in 1844. Bahá'ís are prohibited from owning property, entering certain careers, and barred from higher education in Iran. The Bahá'í community has responded to this formal exclusion through non-violent means. For example, establishing their own underground university known as the Bahá'í Institute of Higher Education (BIHE) which is primarily operated virtually and by volunteer faculty and staff. Although the Iranian government has continuously attempted to shut down BIHE, the institute has grown since its establishment in 1987 to offer 38 programs and accepts approximately 450 new students annually. BIHE's existence and growth exemplify perseverance and resilience under intergenerational pressure and makes for an excellent case study to examine resiliency and forms of non-violent resistance. Using qualitative methodologies including qualitative interviews, surveys, interdisciplinary comparative theoretical research, and statistical analysis, this thesis investigates the nature of resiliency among 15 BIHE alumni. It shows that common theories of resiliency do not adequately account for how resiliency is modeled, taught, and adopted. Therefore, this study proposes that resiliency is a socially embedded process that propels both the individual and the community forward. Additional themes that emerged in defining resiliency among participants included developing individual qualities and characteristics, advancing resources within the community, improving life circumstances, tools of resistance, a non-violent approach, and means of seeking justice.

Keywords: resiliency, resistance, oppression, Bahá'í, Iran, minorities, virtual education
\end{abstract}




\section{Acknowledgements}

I am most grateful to my supervisor and mentor, Dr. Melanie Adrian for her steadfast support and guidance at all stages of this research. Her qualities of heart and mind truly have allowed me to undertake this research endeavour with constant encouragement and resolve. Dr. Adrian's insights and perspectives have constantly challenged me to think in new ways and grow in my understanding and skills. I have deep appreciation for Dr. Adrian's mentorship and the many opportunities that she has guided me to in the discourse of religious freedom. I hold deep admiration for how she combines a community-oriented purposefulness with a high standard of excellence in all her endeavours. Through thoughtful and conscientious action, she embodies how to respond to injustice, which is at the root of this research.

I am thankful to Carleton University and feel honoured to have conducted this particular research at Carleton, the first university to recognize degrees and accept students from the Bahá'í Institute of Higher Education, and the catalyst that led other universities to follow, opening meaningful opportunities for Bahá'ís from Iran. I am grateful for the generous support from the Department of Law and Legal Studies at Carleton University and Research Impact Canada which allowed me to pursue my research interests on religious freedom. I am also grateful to my second reader, Dr. Trevor Purvis for his enthusiasm, encouragement and constructive guidance, Dr. Evelyn Maeder for her constructive feedback and introducing new interdisciplinary perspectives to my research, and my thesis defence Chair, Dr. Sheryl Hamilton for making my defence an encouraging and empowering experience. Further, I would like to thank Dr. Christiane Wilke for positively impacting my experience at Carleton and expanding my consciousness on human rights. Additionally, I would like to thank Andrew Squires and Julie Furber for their patience and guidance as I navigated through my research at Carleton. 
I wish to express gratitude to Corinne Box, Dr. Michael Karlberg, Pegah Seisan, Dr. Roshan Danesh, Saleem Vallaincourt, Dr. Shakib Nasrullah, and Taban Behin for their time and expertise in advancing my conceptual framework and expanding my network of participants. I also want to thank Shayda Sobhani for her invaluable and generous assistance of a close reading of this thesis.

I am deeply appreciative of my family and close friendships for continuous encouragement and support, who graciously acted as pillars of support throughout my master's degree. I feel grateful to have been raised in and surrounded by a community that hold strong values of challenging inequalities and social ills through the acquisition of knowledge and education. I have been fortunate to witness immense strength in the face of adversity from my network of loved ones, which is at the heart of my connection to this research on resiliency.

Lastly, I wish to thank the fifteen resilient and courageous voices that participated in this case study and shared their narratives to shed light on the experience of Bahá'ís living in Iran. Their commitment to education, and sacrifice and dedication to a greater good is moving and profound. Thank you to the Bahá'í Institute for Higher Education for providing a unique response to oppression for all your students and creating a basis of this research. The resiliency and sacrifices of the Bahá'ís in Iran have guided me in my education and continue to give me strength in overcoming challenges. 


\section{Table of Contents}

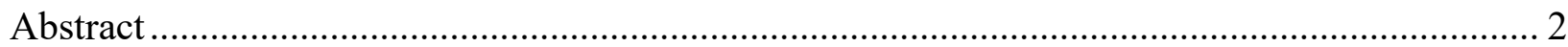



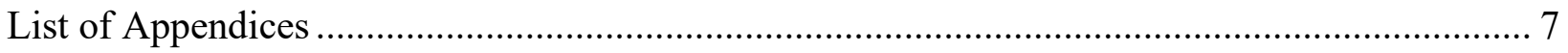

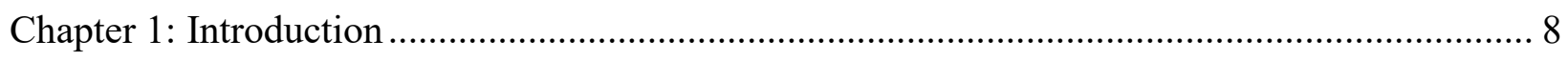

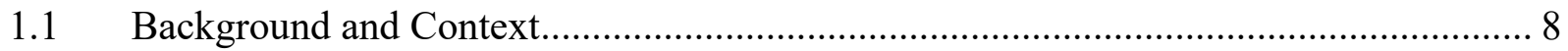

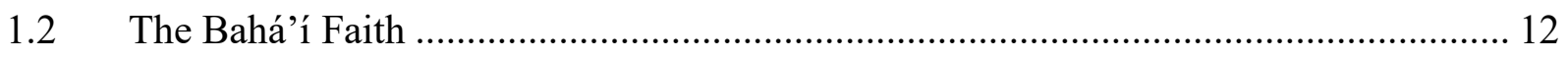

1.3 Lack of Formal Recognition in Iran................................................................... 13

1.4 Persecution of Bahá'ís in Iran after the Islamic Revolution .................................... 17

1.5 The Bahá'í Institute of Higher Education (BIHE) ................................................. 25

1.6 The Role of Education and the Bahá'í Faith........................................................ 30

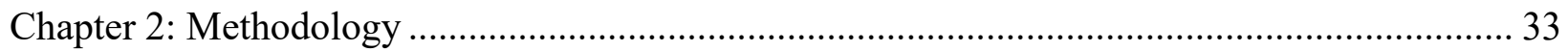

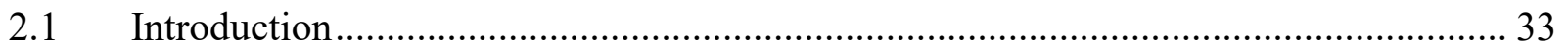

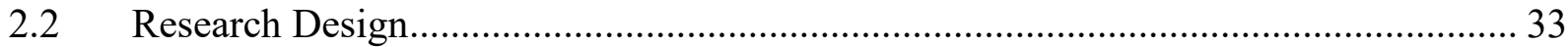

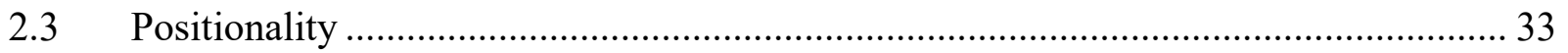

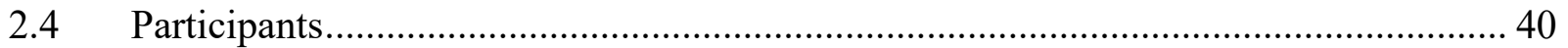

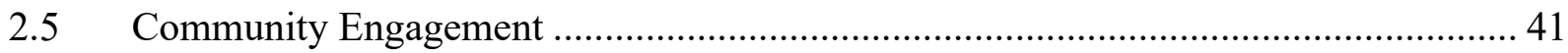

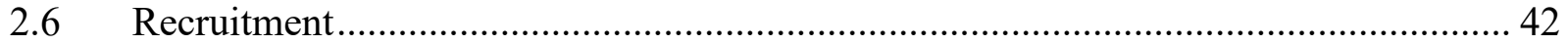

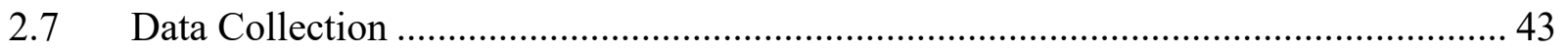

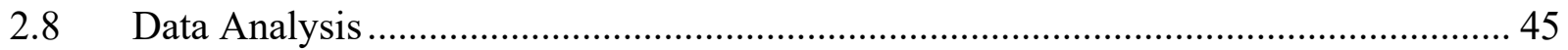

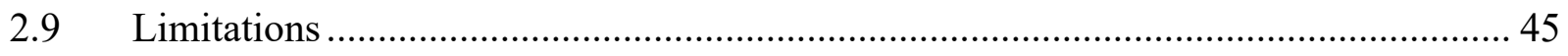

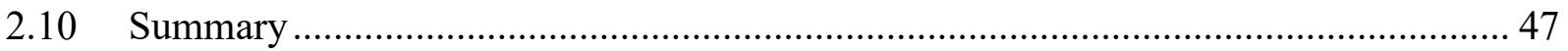



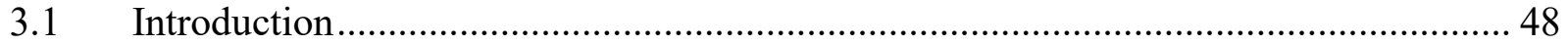

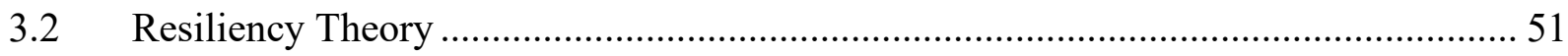

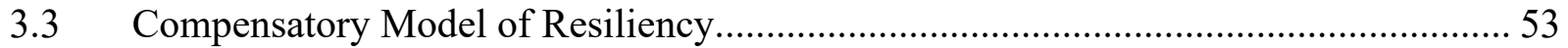

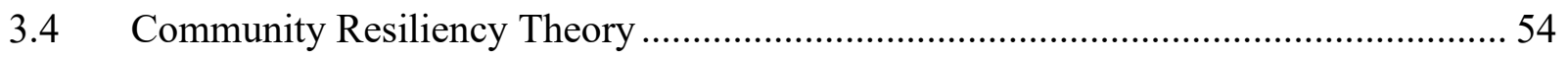

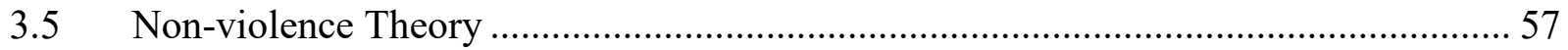




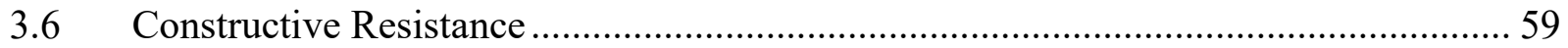

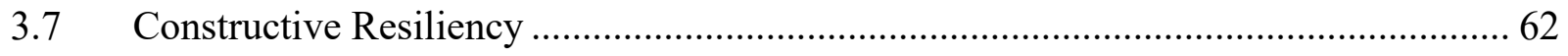

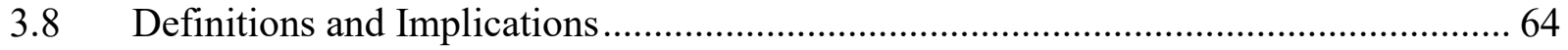

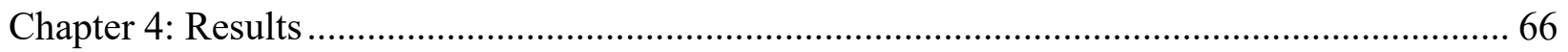

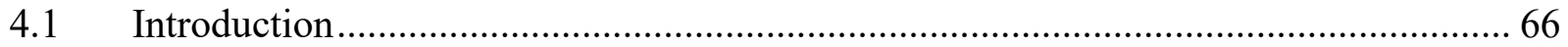

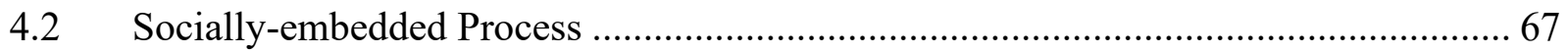

4.3 Advancing Resources within the Community ................................................... 70

4.4 Building Capacity and Qualities in the Individual.................................................. 74

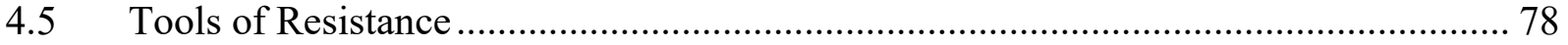

4.6 Improved Outcomes and Circumstance ............................................................ 82

4.7 Lack of Barriers and Forward-Propelling Outcomes .............................................. 86

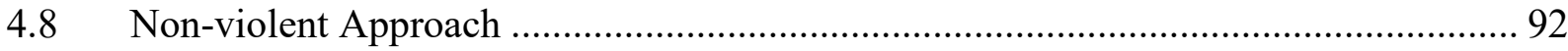

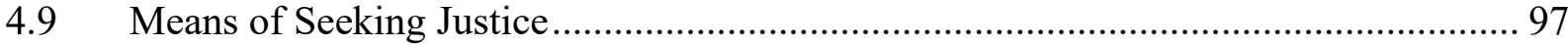

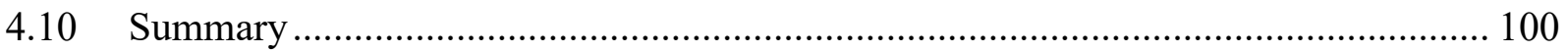

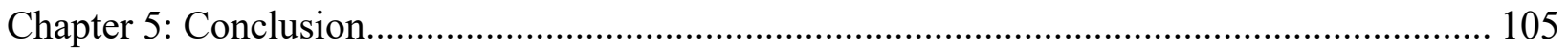

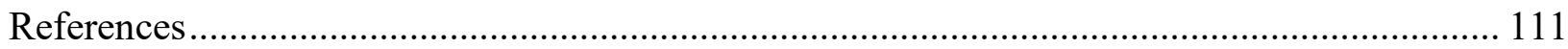




\section{List of Appendices}

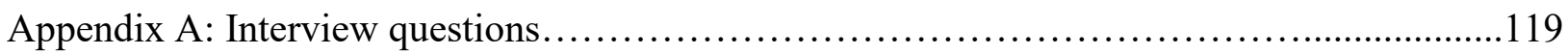

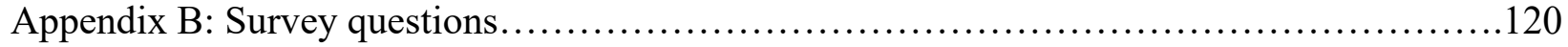

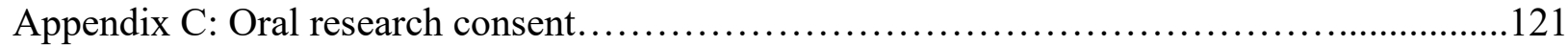

Appendix D: Research consent form ........................................... 123

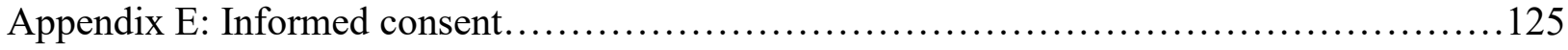

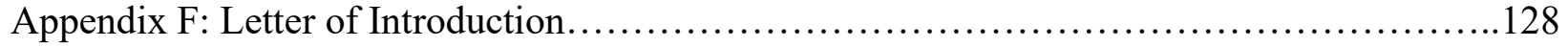

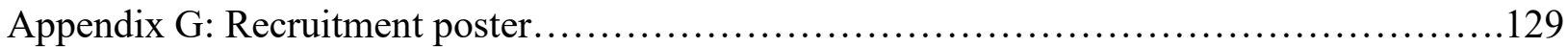




\section{Chapter 1: Introduction}

\subsection{Background and Context}

Bahá'ís in Iran have been generationally and systematically persecuted through violent forms of oppression. Iran's denial of the status of the Bahá'í faith as a religious group has led to the development of policies targeting members of the Bahá'í community, including the exclusion of members from higher education. The Bahá'í Institute of Higher Education (BIHE), the Bahá'í community's underground university in Iran, educates young Bahá'ís; allowing them to have access to knowledge and formal degrees. Building a community centered on justice, while simultaneously advancing individually and collectively, is the response to violence and oppression this case study examines in relation to resiliency. Their human rights have been severely undermined, undercut, and repressed for generations. Attempts to marginalize the Bahá'í community have continuously been made through violent acts of execution, arbitrary imprisonment, arrests, interrogation, raiding of homes, and various forms of cultural and social stigmatization. Bahá'ís also continue to face economic consequences such as the loss of pensions, confiscation of properties, and theft of monetary savings (Landinfo Country of Origin Information Centre, 2017). This thesis explores the particular response from Bahá'ís in Iran to their formal exclusion from higher education. An act of discrimination which is preventing an entire population to continue their education, thus excluding them from excelling in careers and fields that demand a university education.

BIHE has persevered over 30 years while their student body and faculty were personally targeted, and the institution faced continuous attacks. In an age where the forms and ways of resiliency are top of mind, I wondered how resiliency is shaped by the people and institution of BIHE. Graduates of BIHE are now internationally recognized, despite their degrees being 
illegitimate domestically. This underground university in Iran has provided students with the opportunity to gain knowledge, degrees, critical thinking skills, and develop a distinguished form of resiliency. Beyond practical opportunities, the establishment of BIHE has provided a sense of belonging, hope, and strength in a scene of chaos and persecution, as one participant from this study described (2020):

Do you remember how Hogwarts was a big safe place for all these wizards and little kids? BIHE was the same for me. When I was accepted it was like getting an acceptance letter from Hogwarts to go to wizard school. It sounds really silly, but for me it was this feeling that wow, I got admitted to a university and I am going to BIHE. It was this wonderful place I was waiting to go to. I always think about BIHE as something that shows the strength and the unity of the Bahá'i community. I think because I grew up in a minority community that was under a lot of pressure and we went through a lot, and Bahá'ís are still going through a lot, if I got a chance to be a part of this school, it was an honour for me. I got to be a part of something that was very special and that helped Bahá'ís who wanted to go to school. It felt so valuable to me. It was like the way all those people were trying to attack Hogwarts, but they kept it going. I felt we needed to keep BIHE going. I felt that I have to fight for it. I have to be there for it.

BIHE was this participant's sacred place and refuge in a society where Bahá'ís are continuously and meticulously denigrated in different areas of their lives. The existence of an alternative educational structure created a safe and special place for Bahá'í students. Its functioning was more than a space to receive knowledge, but also a place of acceptance to learn and grow. Despite many attempts to shut down BIHE (e.g., leaders being arrested, raids confiscating educational materials), the strength of the community prevailed. 
The interdisciplinary theoretical framework and outcomes of this study reflect how participants understood concepts of resiliency and strategies to combat oppression. In examining how resiliency is shaped through education in the context of systematic persecution, this case study questions the scope of resiliency and suggests that we need a wider definition that addresses intergenerational persecution. In examining resiliency in this case study, participants discuss how they perceive themselves and how they have navigated their situation as being Bahá'ís in Iran.

Common definitions of resiliency discuss resiliency as a tool of providing positive outcomes, focusing on adaptability and the returning to a previous state regardless of inflicted trauma. However, participants from BIHE understand resiliency in their own context, which can shed light on resiliency interventions in diverse settings. Although noteworthy and positive, current definitions of resiliency may only be relevant to specific contexts such as in a clinical setting. This study proposes that resiliency of a minority community responding to violence with education goes beyond the limiting or restrictive factors of standard definitions of resiliency. I attempt to offer a framework which discusses the propelling nature of resiliency that participants described in qualitative interviews. In this case study, participants identify their resiliency as the reason why they thrived and continued forward. Although this work is specific to one minority responding to systematic oppression, the lessons from their experience may have implications for other minorities and justice-seeking groups.

I attempt to better the definition of resiliency defined by participants as a socially embedded process. Themes that emerged in defining resiliency among participants included: developing individual qualities and characteristics, advancing resources within the community, improving life circumstances, tools of resistance, a non-violent approach, and means of seeking 
justice. This approach and understanding of resiliency differ from many theories which do not contextualize adversity caused by intergenerational persecution.

Resiliency itself cannot respond to adversity as it has no agency. Only humans who have resiliency can respond to adversity. I discuss how participants experienced the process of developing resiliency and the quality of it. The socially embedded nature of resiliency is intertwined with the community and the individual, which fosters and fuels resiliency. This description resonates with the constructive resiliency framework which will be further explored in detail. Constructive resiliency is distinguished from other theories which do not fully appreciate the embedded nature of the development of resiliency both as a process and as a quality.

In this chapter, I will first briefly discuss the background of the Bahá'í faith to offer a contextual framework of the community at the heart of this study. Following, I will discuss how a lack of recognition has impacted this specific minority community in channeling persecutory efforts. In addition, I will outline the numerous forms of persecution that Bahá'ís in Iran have experienced from the post-Islamic revolution onwards. I will then provide a background of BIHE, the role that education plays in the Bahá'í faith, and discuss how it relates to this case study. In Chapter 2, I will discuss the methodology used for this case study. In Chapter 3, I will discuss the theoretical framework used to ground this research in understanding resiliency among this population. I will examine resiliency theory, the compensatory model, non-violence theory, community resiliency, constructive resistance, and constructive resilience in relation to this case study. In Chapter 4, I will present the data and results of this study and show how this particular minority and context shift our understanding of resiliency. In Chapter 5, I will present an overview of this case study and provide future direction for future research endeavours and 
implications. I have also included materials used in this study including oral research consent on Appendix C, research consent of online survey on Appendix D, samples of email invitations, informed consent form on Appendix E, letter of introduction sample on Appendix F, and the recruitment poster on Appendix G.

\subsection{The Bahá'í Faith}

The Bahá'í faith is a monotheistic religion with over five million followers worldwide (Momen, 2019). Since its inception in 1844 in Persia (Cameron \& Ghanea, 2018), the Bahá’í religion comprises followers of approximately 2,100 races, ethnic groups, and various indigenous groups (Buck, 2020). Bahá'ís believe in the unity of all religions; that all humanity is under one God. They believe that all of the world's major religions are a part of unfolding chapters in teachings for humankind and that the writings of its founder, Bahá'u'lláh represent guidance from God for this period in time. Bahá'ís consider Bahá'u'lláh, who was born in Iran in 1817, to be the most recent religious messenger of God. They believe that Abraham, Buddha, Jesus Christ, Krishna, Muhammad, Moses, Zoroaster, and others are messengers of God and a part of this progressive development (Bahá'í International Community, 2017). Bahá'ís believe in the unity of races, elimination of prejudice, the equality of men and women, universal education, the elimination of extremes of wealth and poverty (Warburg, 1999). They seek a spiritual solution to economic problems, establishment of an international auxiliary language, the harmony of science and religion, the independent investigation of truth, and the creation of a world commonwealth of nations that will keep peace through collective security (Warburg, 1999).

The Bahá'í community has sought, and been granted, formal status in a number of collaborative international institutions. This includes registration with the United Nations as a 
nongovernmental organization since 1948, as well as consultative status with the United Nations Economic and Social Council (ECOSOC) and the United Nations Children's Fund (UNICEF), as well as accreditation with the United Nations Environmental Program (UNEP) and the United Nations Department of Information (DPI) (Baha'i International Community Representative Offices, 2021). Although the Bahá'í community is not recognized in Iran, they have formal status among internationally recognizable organizations

Since its inception in Iran in 1844, Bahá'ís have faced ongoing forms of persecution (Clarken, 2009) despite being Iran’s largest religious minority (Manocha \& Tahzib, 2018) with approximately 400,000 Bahá'ís living in Iran (Momen, 2019). Over the past 200 years, Iran's political landscape and structure have changed under different forms of leadership. Yet, Bahá'is in Iran continue to experience forms of persecution and attempts of an "ideological genocide" (Smith, 1998, p. 8). Momen (2005) describes the situation of Bahá'ís in Iran as a "suspended genocide" (p. 239) or an "arrested genocide" (p. 239) to reflect a situation which could quickly escalate and deteriorate to a full genocide. The 15 individuals that participated in this study were born into the Bahá'í faith in Iran and attended BIHE as a result of this persecution.

\subsection{Lack of Formal Recognition in Iran}

The lack of recognition of a minority is the precursor to further exclusion socially, legally, and politically, and is demonstrated through persecution. The initial act of recognition of a minority religion by their government is a central point in protecting minorities. Patten (2014) discusses the distinct meaning of recognition whereby it is the act of the state to recognize a conception and to accommodate and assist in a just and fair approach by fulfilling deeper commitments. This process of recognition described by Patten (2014) is not present for Iranian Bahá'ís. Without recognition, the government can apply specific rationalization for exclusion to 
justify persecution with serious consequences for the members of the minority. The internal logic that Iran developed to justify persecution to the Bahá'ís in Iran is based on the Iranian rulers' initial lack of recognition and exclusion since 1844. Iran's denial of the status of the Bahá'í faith as a religious group has led to the development of policies targeting members of the Bahá'í community.

Acknowledging this lack of recognition, Heiner Bielefeldt, the United Nations Special Rapporteur on freedom of religion or belief, stated that "the Bahá'ís have always been a marginalized and vulnerable group devoid of proper legal protections because Iran's constitution does not officially recognize them as religious minorities" (United Nations Human Rights Office of the High Commissioner, 2016). The impact of a lack of religious recognition was described in a 2020 report by the United Nations Special Rapporteur on Freedom of Religion or Belief, Ahmad Shaheed, where he stated how "the failure to eliminate discrimination, combined with political marginalization and national attacks on identities, can propel trajectories of violence and even atrocity crimes" (Lederer, 2020). Regarding Bahá'ís in Iran specifically, Shaheed also shared that "unrecognized religious or belief groups, including the Bahá'ís are unable to access employment, housing, university-level education, health care and social services, including pensions" (Lederer, 2020). The lack of conceptual recognition that Bahá'ís experience in Iran directly correlates with their access, freedoms, and protections.

Amy Guttman (1994) discusses how a minority group requires public authorities such as governments to recognize the unique differences of its members to thrive. She discusses how the act of recognition is a central point in protecting minorities. Guttman (1994) further describes that true equality requires recognition of different cultural identities and that without such recognition, equality cannot exist. Although Bahá'ís are not specifically classified as a cultural 
group, they are a distinct religious minority group in Iran. Guttmann (1994) discusses how treatment of different groups as equals requires formal public acknowledgement of differences. Further, Modood (1998) also discusses the need for policies of public multiculturalism which requires the recognition of religious minorities in societies with disadvantaged religious minorities. The Iranian government and public authorities have not publicly acknowledged the Bahá'í faith as a distinct religious group and Bahá'ís have become targeted instead of protected. Essentially, Bahá'ís have not received the status of a religious minority in Iran and without this official acknowledgement they are not granted basic human rights by the Iranian government. Thus, according to Guttman's (1994) perspective, equality in Iranian society cannot exist for Bahá'is, and this lack of recognition has impacted all aspects of their lives. In fact, Iran's government and religious leaders who hold political power have used charged labels to classify and misrepresent the Bahá'í faith as a "political movement" (Pistor-Hatam, 2017, p. 92) and not as a religious minority. This particular use of language and manipulation has led to erroneous grounds and rationale to persecute Bahá'ís. The inaccuracy of defining Bahá'í identity has led to further misrecognition and justification for persecution.

In contemporary Iranian society, communities are made up of individuals who hold certain values, belief systems, and principles. Although a community is composed of individuals, in reference to inequality, the influence and responsibility remain with governments to define and uphold standards. Guttman (1994) argues that a minority group's requirement of a secure cultural context is dependent on the obligation of a government to help preserve that culture against a majoritarian culture. The argument applies to the need for political recognition to preserve people of a minority religion against a majoritarian religion. Guttman (1994) states: 
Liberal democratic states are obligated to help disadvantaged groups preserve their culture against intrusions by majoritarian or 'mass' cultures. Recognising and treating members of some groups as equals now seems to require public institutions to acknowledge rather than ignore cultural particularities, at least for those people whose self-understanding depends on the vitality of their culture. This requirement of political recognition of cultural particularity - extended to all individuals - is compatible with a form of universalism that counts the culture and cultural context valued by individuals as among their basic interests.

The basic requirement of recognition from a political sphere for minority groups which Guttman (1994) argues is not present for Bahá'ís in Iran. Taylor (1997) describes the repercussions and consequences of a lack of recognition, stating that "nonrecognition or misrecognition can inflict harm, can be a form of oppression, imprisoning someone in a false, distorted, and reduced mode of being" (p. 25).

This categorical misrecognition which Taylor discusses, is directly impacting Bahá'ís in Iran in their ability to apply to university. In the demographic portion of the application, Bahá'ís are unable to identify their religious affiliation under the religion category, and therefore the applications are considered incomplete and invalid (Yazdani, 2015; Bahá'í International Community, 2016). The lack of formal recognition that Bahá'ís in Iran experience, and its systematic exclusion and persecution amounts to how Smith (1998) describes an "ideological genocide" (p. 8) or Momen (2019) describes as a "cultural genocide" (p. 258). The act of recognition is a central point in the protection of minorities and this protection is deficient for Bahá'ís in Iran. "Misrecognition shows not just a lack of due respect. It can inflict a grievous wound, saddling its victims with a crippling self-hatred. Due recognition is not just a courtesy we 
owe people. It is a vital human need" (Taylor, 1997, p. 26). Thoughtful exclusion and thoughtful inclusion at different points in time have impactful consequences on individual and collective lives. By denying recognition of Bahá'ís and their status as a religious minority, formal policies and informal norms have fed into the systemic oppression at all levels in Iranian society, thereby informing educational policies.

\subsection{Persecution of Bahá'ís in Iran after the Islamic Revolution}

The public lack of recognition and intentional misrecognition has informed sophisticated methods of systematic persecution concerning Bahá'ís in Iran. This section will summarize some of these forms that have taken place since the inception of the Bahá'i faith in Persia, but in no wise fully describe in detail the complete picture of persecution faced by Bahá'ís in Iran. Throughout the Qajar dynasty, the Shah era, and the post-Islamic revolution period Bahá'ís have experienced state-sanctioned systematic persecution. Since 1844, Bahá'ís and religious leaders have been executed and persecuted. Although significant and violent, for the purpose of this research I will focus on the post-Islamic revolution period in providing context of the current landscape of persecution through education for Bahá'ís in Iran.

The declaration of Iran's theocratic republic in 1979 led to a referendum naming the country the Islamic Republic of Iran (PBS Newshour, 2010). Under Ayatollah Khomeini’s leadership, the new government was guided by the country's Islamic principles with political power (PBS Newshour, 2010). The revolution in 1979 commenced a new wave of persecutions as the new regime was explicit that it did not recognize Bahá'ís as part of a religious group (Nash, 1982). Between 1978 and 1979, the Bahá'í national headquarters in Tehran and Bahá’í buildings in different provincial capitals were confiscated by militiamen that were devoted to Ayatollah Khomeini (Landinfo Country of Origin Information Centre, 2017). Additionally, 
leaders of the anti-Bahá'í society, "Hojjatiyeh”, assumed many influential positions within the new republic (Tavakoli-Targhi, 2008) leading to further formal persecution and vulnerability of Baha'is in Iran.

At this time, various forms of violence against Bahá'ís took place on over fifty occasions in Iran including arson, mob attacks, and murder (Landinfo Country of Origin Information Centre, 2017). Bahá'í sacred sites were destroyed including the home of Bahá'u'lláh near Takur and the home of the Báb in Shiraz (Zabihi-Moggadam, 2016). Another sacred space, the site of the House of the Báb, which was destroyed by a mob, was converted into a road and a public square (Cameron \& Momen, 1996). Between 1978 and 1981, a total of 22 Bahá'í centres and cemeteries were destroyed, along with 300 Bahá'í homes and an unknown number of Bahá'í businesses were burned, looted, or destroyed (IHRDC, 2006; Nash, 1985). The state also seized the properties of Bahá'ís who were executed or murdered instead of following standard procedures of inheritance to next of kin (IHRDC, 2006). During this period, Bahá'ís were dragged to mosques in efforts to force them to recant their faith (Nash, 1985). Following the revolution in 1979, Bahá'ís in the country were collectively dismissed from their positions in government departments and denied the right to work. Retired Baha'i government employees were denied their pensions (Nash, 1985). This included many doctors, nurses, and teachers who all identified as Bahá'ís (Cooper, 1985). A clinic which belonged to Bahá'í doctors was dynamited and destroyed (Nash, 1985). Without recognition as a religious minority, Bahá'ís lacked any status or ability to dispute the forms of violence and persecution.

In 1985, the Attorney General of the Iranian government announced that summonses would be issued against former Bahá'í civil servants demanding that Baha'is repay the government the salaries they had received during their entire period of employment (Cooper, 1985; Zabihi- 
Moggaddam, 2016). If this was not paid, Bahá'ís who had worked for the government would face imprisonment (Cooper, 1985; Zabihi-Moggaddam, 2016). In addition, government authorities seized the Bahá'í community's central financial institutions — the Nawnahalan Company and the Umana Corporation — which held the titles to all Bahá'í endowments in Iran, including Bahá'í cemeteries and holy sites (Cooper, 1985). The seizures of these two companies resulted in approximately 15,000 Bahá'ís losing their pensions and savings (Cooper, 1985). This economic deprivation led to many Bahá'ís seeking stability outside of Iran and becoming refugees.

Other tactics of economic deprivation included the closure of universities for 3 years in 1980, as part of the Islamic regime's Cultural Revolution to purge Iranian universities of nonIslamic and Western influences. At this time, Bahá'í faculty and students were all dismissed, expelled, and denied access to higher education. At the beginning of the 1981 school year, the Ministry of Education issued an official recantation form that inquired whether students or their parents were Bahá'í, and asking for the identities of their Bahá'í relatives, as well as if they were willing to recant their faith (Zabihi-Moghaddam, 2016). Although Bahá'ís were categorized as solely a "political faction" (Nash, 1985, pp. 77-78) according to Khomeini in his 1978 interview in France, they were being pressured to recant their affiliation and belief in the Bahá'í religion. Iran had previously signed a number of international documents committing to specific relevant areas in human rights. There was a UNESCO's Convention Against Discrimination in Education as well as the International Covenant on Economic, Social, and Cultural Rights were both signed by Iran in 1968 and ratified by Iran in 1975 (Haghani, 2014). The act of signing and ratifying these international documents implies a set of expectations and standards for minorities. 
However, this was prior to the Islamic Revolution and the change in government impacted the discrepancies between the Convention and policies in Iran after 1979.

Regardless, Bahá'ís were still being persecuted during the period of ratification. From 1980 to 1985, executions of Bahá'ís increased at a rampant pace. Within 5 years, 175 Bahá'ís were killed (Zabihi-Moghaddam, 2016). With these executions, there were no options for Bahá'ís to seek retribution through the formal justice system. The inability of Bahá'ís to utilize the justice system in Iran is a direct consequence of this minority group not having recognition or rights as a religious group in their residing country. Reza Afshari (2008), a historian of human rights in contemporary Iran, reported the following:

No credible trial ever took place. None could be charged with any real crime in a credible court. What was even more heart-wrenching was that many of them could have avoided execution if they had professed - nominally, as is often the case in repentance - to have accepted Islam (Afshari, 2012, p. 246).

During this period in June 1983, seventeen Bahá'ís, including seven women and three teenage girls were hung in the Iranian city of Shiraz because they refused to recant their faith (Cooper, 1985). Earlier that same year, Hojjatol-Islam Qazai, the chief religious judge and president of the revolutionary court of Shiraz, issued a warning that was quoted in the February 22, 1983 edition of the newspaper Khabar-i-Junub (Cooper, 1985, p. 13):

Before it is too late, the Bahá'is should recant Bahá'ism, which is condemned by reason and logic. Otherwise, the day will soon come when the Islamic nation will deal with the Bahá' is in accordance with its religious obligations, as it has dealt with other hypocrites who have appeared in more dangerous garb and have satanic religious gathering. (Cooper, 1985, p. 13) 
This explicit content indicates how the government formally approached Bahá'ís in Iran. In addition to threats and executions, over 1,000 Bahá'ís were arrested between 1982 and 1984, and in 1985 over 700 Bahá'ís were imprisoned (Afshari, 2008). The imprisoned Bahá'ís could have been released had they renounced their faith. This also applied to prisoners that were executed because of the death penalty due to their religious beliefs (Afshari, 2011). The lack of recognition of Bahá'ís as a religious minority allowed the Iranian government to follow through with these arrests and executions whilst following their domestic laws, as Bahá'ís were categorized as political criminals and not members of a religious group.

In 1980, Ayatollah Sadiqi, a government leader who arose after the revolution under Khomeini, demanded that all Bahá'ís in government departments be identified, removed, and handed over to revolutionary courts citation. This included Bahá'í teachers under the Ministry of Education. Bahá'í marriages were considered prostitution and were not recognized as legal, and divorces were declared void for this same reason (Galindo, 1988). Infants born from Bahá'í parents were not issued birth certificates. Bahá'í hospitals were nationalized and Bahá'í elderly patients were dismissed (Nash, 1985). Bahá’í companies were confiscated. Nine members of the National Spiritual Assembly of the Baha'is Iran as well as two other Bahá'ís were arrested and abducted to an unknown destination (Nash, 1985) and are believed to have been killed (Landinfo Country of Origin Information Centre, 2017). In 1981, the government instructed overseas Iranian consulates and embassies to not renew passports of Bahá'ís (Nash, 1985). On August 29, 1983, the Iranian Attorney General formally announced a ban on all administrative and community activities of the Bahá'í Faith in Iran. He declared that membership within a Bahá’í administrative institution was a criminal offense (Cooper, 1985). As the situation in Iran became increasingly more difficult for Bahá'ís, many fled and sought asylum in other countries. As a 
response to this hardship, in November of 1984, the International Bahá'í Refugee Office, responsible for coordinating efforts to resettle Iranian Bahá'í refugees was established by the National Spiritual Assembly of Canada at the request of the Universal House of Justice, the world governing body of the Bahá'ís (Cameron \& Momen, 1996).

Shortly after a 15-year-old Bahá'í, Payman Subhabi was killed in 1986, the United Nations Commission on Human Rights adopted a resolution asking its Chair to appoint a new special representative to report to the General Assembly on the human rights situation in Iran, including the Bahá'ís in Iran (Cameron \& Momen, 1996). This led to the discovery of a confidential memorandum regarding the treatment of Bahá'ís. In 1991, the confidential memorandum regarding “The Bahá'i Question” was issued by the Islamic Supreme Revolutionary Cultural Council (Sattarzadeh, 2015). This blueprint formalized the systematic persecution of Bahá'ís in Iran and efforts to dismantle the Bahá'í presence (Cole, 2005). The memorandum, also known as the "Golpaygani Memorandum," was previously signed by Khomeini (Sattarzadeh, 2015). This signature is an indicator of his support and approval of these recommendations (Affolter, 2005). A note in Khomeini's handwriting states that the Supreme Council of the Cultural Revolution's (SCCR) decision seemed sufficient (BIC, 2008, p. 23). This document outlines methods of oppression used to persecute Bahá'ís and specific recommendations on how to block the progress of the Bahá'í community inside and outside of Iran (Affolter, 2005). Below is an English translation of the 1991 "Bahá'i Question" memorandum, outlining the Islamic Republic's plan to block the progress of Baha'is in Iran (Baha'i International Community, 2016). Some of these recommendations which include the use of them, their, and they to refer to the Bahá'ís are as follows: 
The governments' dealings with them must be in such a way that their progress and development are blocked. They can be enrolled in schools provided they have not identified themselves as Bahá'is, preferably they should be enrolled in schools which have a strong and imposing religious ideology. They must be expelled from universities, either in the admission process or during the course of their studies once it becomes known they are Bahá'is. Their political (espionage) activities must be dealt with according to appropriate government laws and policies and their religious propaganda activities should be answered by giving them religious and cultural responses as well as propaganda. Propaganda institutions such as the Islamic Propaganda Organization must establish an independent section to counter the propaganda and religious activities of the Bahá'is. A plan must be decided to confront and destroy their cultural roots outside the country. Permit them a modest livelihood as is available to the general population. To the extent that is does not encourage them to be Bahá'is, it is permissible to provide them the means for ordinary living in accordance with the general rights given to every ordinary citizens such as ration booklets, passports, burial certificates, work permits, etc., Deny them employment if they identify themselves as Bahá'is. Deny them any position of influences such as in the education sector, etc. (p. 94).

This memorandum confirms that the human rights violations against Bahá'ís in Iran was not based on random acts of violence but a matter of patterns in official policy (Zabihi-Moghaddam, 2016). With the existence of an official memorandum, treatment of Bahá'ís by authorities became more official and systematic in contrast to the treatment that they had been subject to in the past (Afshari, 2008). 
The treatment of Bahá'ís in Iran following the Iranian Revolution in 1979, is an indicator of how a lack of previous or initial status and recognition can perpetuate violence and have severe consequences. This was followed by the formal exclusion of the Bahá'í religion in the 1906 Constitution in Iran while including other religious minorities (Akbar, 2021). The only religions that the Iranian Constitution recognizes are Islam, Christianity, Judiasm, and Zoroastrianism (Manocha \& Tahzib, 2018). In 1979, anti-Bahá'í groups were promoted to influential positions within a new government whereby further justification of persecution against Bahá'ís became formally permissible. The persecution against Bahá'ís technically followed the law of the land. Monocha and Tahzib (2018) describe forms of persecution which Bahá'ís in Iran experienced due to their religious identity:

Bahá'ís have been targets of recurrent waves of executions, death threats, mob violence, hostile propaganda and vilification, disappearances, arbitrary arrests and detention, torture, confiscation of individual and communal property and assets, arson, denial of access to education and employment, and even desecration of graves, all aimed at eliminating the community as a viable entity (p. 203).

Bahá'ís in Iran continue to face marginalization, stigmatization, and active persecution. One participant I interviewed shared the economic deprivation her family faced because of their religious affiliation in the following excerpt (2020):

My father and brother were mechanics. There was a Bahá'í religious holiday, I think the Birth of the Báb, and my father closed their mechanic shop for the day. The government came on that day and locked it up and took away their shop. This was 6 years ago, and both my father and my brother can't work. This is one of the situations the Bahá'ís experience. 
Other participants shared stories of their time in prison or of being arbitrarily arrested and interrogated. They also shared the hardship associated with their family members or friends being jailed and persecuted for their faith or involvement at BIHE. These experiences were normalized and almost expected among participants that formerly resided in Iran.

A lack of recognition as a religious group can perpetuate future mistreatment with severe consequences. Perhaps the most striking act of persecution with the most detrimental consequences on generations to come, is the denial of post-secondary education for Bahá'ís in Iran. This act of exclusion is part of the unwavering pattern of discrimination and the systematic effort in inhibiting progress of Bahá'ís (Haghani, 2014). Exclusion of Bahá'ís within educational institutions is conducted systematically (Yazdani, 2015; Bahá'í International Community, 2016). As previously discussed on page 16-17, on public university admission forms, students are asked to identify their religious affiliation. The application only includes slots for Muslim, Jewish, Christian, and Zoroastrian students (Yazdani, 2015; Bahá'í International Community, 2016). Although there are approximately 300,000 to 350,000 Bahá'ís living in Iran (Hassan, 2007), these select choices only include religions that are officially recognized in Iran. There is no option of "other" on admissions forms, effectively disqualifying Bahá'í students as their application form is not complete and therefore invalid (Yazdani, 2015; Bahá'í International Community, 2016). This intentional practice systematically excludes Bahá'ís from accessing higher education.

\subsection{The Bahá'í Institute of Higher Education (BIHE)}

In response to this denial of university education, BIHE was established in 1987. BIHE is a private underground university established for Bahá'ís who are unable to attend university in Iran to "meet the educational needs of young people who have been systematically denied access 
to higher education by the Iranian government" (Khalighy, 2021, p. 12). This unique response to violence and discrimination emphasises social transformation through the establishment of an educational institution versus approaches such as confrontation that can have adverse effects. Lamont et al. (2016) describes the significance of how a response is approached in matters of discrimination in the following excerpt:

Responses matter, because the stress (or "wear and tear") generated during responses may compound inequality and disadvantages. Types of responses may affect health differently, depending on the social context. In such contexts as the workplace, for example, confrontational responses may impact health negatively, in part because of the necessity of maintaining an occupation for mental well-being. Normative responses raise important questions concerning how social change can be produced moving ahead, through individual and collective strategies aimed at social transformation. (p. 9)

The existence of BIHE resonates with Lamont's (2016) work on conscious and responsive strategies producing social change and social transformation, which illustrates how the type of response to a barrier can have long term and adverse consequences as described.

The focus of participants was to identify strategies to overcome rather than engage with strategies that cause further turmoil. This response is characterized by an educational institution that has no formal existence, physical buildings, and recognition in Iran (Khalighy, 2021). The few classes that continue to occur in person take place in the basements and attics of homes with online correspondence. Courses were initially delivered infrequently in-person with correspondence. Due to technological advancements, educational modalities are now virtual with classes being provided online (Novelli \& Selenica, 2014). Remote technology has also enabled professors from recognized international universities to volunteer as faculty and teach 
virtual classes at BIHE (Assadi \& Lloyd, n.d.). One participant shared that former BIHE students would physically submit their assignments through a courier, who would risk their safety traveling from city to city to pick up assignments and hand deliver assignments to the instructor. The courier would wait for the instructor to grade and provide feedback for students and travel from city to city to return graded assignments. Hence, it could take months to receive feedback and communicate with an instructor. The existence of this private mailing system was a response to government officials seizing postal educational materials for BIHE (Assadi \& Lloyd, n.d.). With the advancement of technology and widespread internet access, communication with instructors has become easier (Assadi \& Lloyd, n.d.). However, participants shared classes online are still subject to government interference. They shared frustrations of habitually having their school website blocked by the government. This would happen often, sometimes daily, and IT administrators would have to create new website locations for students to access their school materials.

BIHE has allowed for thousands of students to graduate university. With five faculties, it offers students five associate programs, 18 undergraduate degrees, and 14 graduate degrees (BIHE, 2021a). Over 102 universities accept BIHE graduates into their graduate programs internationally, a number that continues to increase (BIHE, 2021). Thus, BIHE has allowed for opportunity and access to international education for an entire demographic. BIHE is run entirely by volunteers, with over 955 individuals voluntarily contributing as part of the affiliated global faculty and staff members (BIHE, 2021a).

In Iran, many Bahá'í volunteers are faculty members, teaching assistants, administrators, or staff that contribute to the successful operation of a university (BIHE, 2021b). There are also local Bahá'ís that contribute to the operation of the university by hosting classes inside of their 
homes or preparing meals and serving tea during classes. Participants shared how many Bahá'ís also offered accommodation in their homes for students who travelled from out of town to attend in person classes. Outside of Iran, the volunteer academics are known as the Affiliated Global Faculty (Ghadirian, 2008). Volunteers are not necessarily affiliated with the Bahá'í religious community and are often academics that seek to respond to injustice by contributing their time and expertise to educate students that do not have access to higher education. The global affiliated faculty have contributed to the caliber of course content at BIHE. Perhaps even more impactful, the global affiliated faculty have contributed to the increased confidence, and encouragement of students who face a discriminatory reality. One participant in an interview shared the following sentiment (2020):

I remember one of my teachers, at the same time he had a class at UCLA. He always told us that the way I am teaching you is the way that I'm teaching at UCLA right now. It had a really good feeling. I have a teacher from UCLA, and I have the same course as UCLA students.

The global affiliated faculty at BIHE contributes more than just disseminating content to a group of students. Their contributions provide students with purposefulness and motivation. Within a negative and violent environment, participants were able to grasp onto hope and positivity, impacting how they viewed themselves and their abilities.

In addition, many BIHE alumni volunteer their time as teaching assistants or instructors despite living abroad. Participants understood this as a duty of contributing to BIHE to allow future generations to thrive. This included participants in their graduate or doctoral studies, that concurrently volunteered their time to contribute at BIHE remotely in some capacity. The 
purpose for their time, sacrifice, and energy was based on BIHE's survival and future educated generations.

Although degrees from BIHE are recognized and accepted at institutions like Harvard, Yale, and Columbia, they are not recognized in Iran. This was recently demonstrated in 2011 by the Ministry of Science and Technology of Iran which formally declared that all issued diplomas and degrees by BIHE have no legal validity (Novelli \& Selenica, 2014). Graduates from BIHE are unable to formally use their degrees towards their careers in Iran. Formal positions requiring accreditation, including teachers, accountants, and engineers are not open to BIHE graduates regardless of their education. The exception of being hirable would be on a case-by-case basis, such as if private business owners were willing to overlook their lack of accredited degree and hire graduates based on likability. This resulted in one participant who had graduated with an accounting degree working without pay for 4 years at an accounting firm, while supporting a family. Finally, after 4 years, the firm was willing to overlook this participant's lack of recognized education and hire them with pay. If BIHE graduates had financial resources to afford international tuition and means to leave their home country, they could apply to graduate programs abroad using their BIHE degree for admissions. With a recognized graduate degree from an institution outside of Iran, they could apply for jobs within Iran. However, with the stigma associated with Bahá'ís, they are still limited in the formal roles they are able to obtain.

The community-oriented structure of BIHE allowed this educational institution to be established and continue to exist. The operation of an educational institution that is grounded in elements of sacrifice, generosity, and service among volunteers, has allowed for the betterment of circumstances and outcomes among an oppressed minority group. The mentality of 
contributing time for the collective group has made BIHE a socially embedded process where the community and the individual engage hand in hand.

\subsection{The Role of Education and the Bahá'í Faith}

The existence of BIHE as an educational institution is directly affiliated with the theological orientation of the Bahá'í faith. Although access to education is a basic standard that all citizens of a country should have, education in particular plays an important role in the values and beliefs of Bahá'ís. The context of BIHE is grounded in aspects of the Bahá'í religion. The value of education is at the forefront of Bahá'í principles and teachings. This is demonstrated in the following three excerpts from the Bahá'i writings:

Strain every nerve to acquire both inner and outer perfections, for the fruit of the human tree hath ever been and will ever be perfections both within and without. It is not desirable that a man be left without knowledge or skills, for he is then but a barren tree. Then, so much as capacity and capability allow, ye needs must deck the tree of being with fruits such as knowledge, wisdom, spiritual perception and eloquent speech (Bahá'í Reference Library, 2008a, p. 3).

Arts, crafts and sciences uplift the world of being, and are conducive to its exaltation. Knowledge is as wings to man's life, and a ladder for his ascent. Its acquisition is incumbent upon everyone (Bahá'í Reference Library, 2008b, p. 4). Make every effort to acquire the advanced knowledge of the day, and strain every nerve to carry forward the divine civilization. Establish schools that are well organized, and promote the fundamentals of instruction in the various branches of knowledge through teachers who are pure and sanctified, distinguished for their high standards of conduct 
and general excellence, and strong in faith; scholars and educators with a thorough knowledge of sciences and arts (Bahá'í Reference Library, 2008c, pp. 24-25).

Furthermore, Bahá'ís understand the role of education and its implications for oppression on a global scale of progress and social change. The act of responding to injustice through education is part of a larger path to social change and justice. The following two excerpts from the Bahá'í writings emphasize this role and impact of education on society:

The primary, the most urgent requirement is the promotion of education. It is inconceivable that any nation should achieve prosperity and success unless this paramount, this fundamental concern is carried forward. The principal reason for the decline and fall of peoples is ignorance. Today the mass of the people are uninformed even as to ordinary affairs, how much less do they grasp the core of the important problems and complex needs of the time. ('Abdu'l-Bahá, p.109)

Observe carefully how education and the arts of civilization bring honor, prosperity, independence and freedom to a government and its people. ('Abdu'l-Bahá, p. 111) As demonstrated through the above texts, education is a central value within the Bahá'í religion. It is theologically linked with the knowledge, teachings, and principles of the Bahá'i faith. Education counters ignorance, strife, and contention. It is no wonder that although Bahá'ís are persecuted in a number of ways, they have responded by seeking and obtaining education. For example, Bahá'ís in Iran lose their pensions because of their religious affiliation, but the Bahá'í community has created an alternative educational institution. The collective dedication and concentrated efforts of the Bahá'í community have not been devoted to creating an alternative pension solution. The acquisition of education itself reflects the Bahá'í religion and its values. 
The teachings of the Bahá'í religion have informed the community's unique response to violence faced in Iran (Manocha \& Tahzib, 2018). The role of education in the Bahá'í faith is applicable to individual and community development as well as global social change and has an integral role in what it means for Bahá'i's to practice their religion. The direct relationship of education in the Bahá'i faith and the endeavours of BIHE, provide important context to the establishment of BIHE. 


\section{Chapter 2: Methodology}

\subsection{Introduction}

The purpose of this chapter is to introduce the research methodology of this case study on resiliency among alumnus from BIHE. This chapter will discuss the methodology of this research and explore the research design, positionality, study participants, community engagement, recruitment, data collection, data analysis, and limitations of this research. Furthermore, this case study and methodology was approved by the Carleton Ethics Board.

\subsection{Research Design}

A qualitative methodology was chosen to conduct an in-depth exploration of $15 \mathrm{BIHE}$ alumni. Each participant took part in an interview and survey which occurred online for approximately 2 hours between April and November 2020. Recruitment methods included contacting community institutions to distribute recruitment posters, as well as snowballing which will be further discussed in Chapter 2.6. The qualitative methodological approach provided an in-depth exploration of this case study. "Qualitative methods may be preferred when deeply exploring a topic while trying to preserve the context" (Rust et al., 2017; p. 1305). In addition, semi-structured interviews and surveys with both close-ended and open-ended questions allowed for extensive research analysis. Interview and survey questions are included in Appendices A and $\mathrm{B}$.

\subsection{Positionality}

The unique positionality of a researcher is intertwined into the research project (Bourke, 2014). With this in mind, I reflect on my positionality vis-a-vis this study as it impacts the ability to recruit and build rapport with participants. It is necessary "to acknowledge who we are as individuals, and as members of groups, and as resting and moving within social positions" 
(Bourke, 2014, p. 3). My positionality as both an insider and outsider in relation to the participants affects what questions are asked, including what is implicit versus explicit between researcher and participants. I am a member of the Bahá'í community and thus share a faith-based connection with participants. Having learned about the persecution of Bahá'ís in Iran and their innovative response to violence, this research area was of particular interest for me in learning about freedom of religion. Although I personally have not faced violence due to my religious affiliation, my parents fled Iran due to the religious persecution they faced. In understanding my identity as a Master's student researching and studying with ease in Canada, I reflected on what life would have looked like if my parents had not fled Iran due to the religious persecution they faced. I would have likely been a student at BIHE. The opportunities that I have had access to outside of Iran have given me a strong sense of gratitude; consequently, providing me with a sense of responsibility to highlight the unique response to human rights violations from Bahá'ís in Iran.

In addition, this area of freedom of religion was of particular interest to me because it proposes a solution to a problem, rather than solely highlighting human rights violations and atrocities. This solution-based approach to violence also does not need to be exclusive to Bahá'í students living in Iran. Further developing the definition of resiliency discussed in this study can ideally have an impact on other minority communities or justice seeking groups in oppressive contexts.

While the participants and I share a faith, it is important to highlight the differences between myself and participants that impact the study. I do not share their lived experience of persecution and a multitude of restrictions, including accessing higher education. I acknowledge my privilege and power dynamics between myself and participants that this entails. There is a 
significance in acknowledging the distinction and difference between being connected to a research endeavour versus being the subject of a research endeavour. In significant and experiential ways, I remain an outsider to the experiences that participants faced.

My positionality as a fellow community member could have also impacted their reluctancy to be fully open and vulnerable in interviews (Greene, 2014). There may be a certain set of rules and standards within any religious community that are considered norms and silent expectations. Participants could be making assumptions about my lifestyle and behaviours which could affect what they share or choose not to share consciously or subconsciously. For example, if a participant struggled with an addiction issue, which was relevant in their experience of resiliency, they may feel uncomfortable divulging that information to me in the interview and prefer to adhere to cultural social norms. However, if I was purely an outsider, there may be a different set of social norms between the interviewer and participant and therefore they may feel less intimidated in an interview setting.

My position as a member of the Bahá'í community with participants has made me both an insider in their community and an outsider. As mentioned earlier, participants in this study all had Iranian heritage, having previously studied and lived in Iran. Although I also have an Iranian background, my experience differs as I have never been to Iran due to the persecution of Bahá'ís. This made me culturally and linguistically a partial outsider relative to the participants that I interviewed. I am a second-generation person born in North America and my experience differs vastly to their first-generation experience. My outsider status may have created walls and barriers between myself and interviewees leading to less expressive interactions (Merriam, et al., 2001).

Another layer of my unique positionality in this case study is my relationship to the persecution of Bahá'ís in Iran. Although I do not share the lived experiences of participants, I 
have a particular attachment to the persecution that they have faced as many of my family members have faced similar acts of violence before they fled Iran. My childhood consisted of hearing stories about my mother and her siblings being stoned as children because they were Bahá'í. My maternal grandmother could not be issued a passport to leave Iran safely because she was a Bahá'í. My paternal grandmother was an elementary school principal and teacher and lost her job on the grounds of her religious identity. One of my father's earliest memories was his teacher in primary school singling him out in front of his classroom as a Bahá'í and announcing to the class that my father's religion was not a religion, but a political movement associated with politics to do with England and tobacco sales. This encouraged his peers to bully him based on his religious identity and is an example of the social stigmatization Bahá'ís in Iran experience at any age. This list could go on, and on the spectrum of persecution that Bahá'ís have faced in Iran, these stories are mild. Unfortunately, narratives like these are not uncommon and are likely an unspoken assumption between me and other individuals with an Iranian Bahá'í background. Participants in this case study are likely to assume that my family faced persecution in Iran and that my relationship and interest in this area of study could be influenced by my personal relationship to the persecution they faced.

This perceived role of acting as both an insider and an outsider while also being an interviewer results in complex positionality dynamics (Merriam, et al., 2001). "Within positionality theory, it is acknowledged that people have multiple overlapping identities. Thus, people make meaning from various aspects of their identity" (Kezar, 2002, p. 96). Perhaps community and cultural similarities allowed for greater rapport and strengthened relationship building within interviews and in turn made discussions more fruitful (Greene, 2014). In contrast, the differences between the experiences of the participants and myself may have added 
a certain level of formality within the interviews. I understand this healthy distance as a strength, as participants needed to thoroughly explain their story without assumptions of my previous knowledge. These complex layers of potential strengths and potential obstacles demonstrate Kezar's (2002) understanding of “multiple overlapping identities” (p. 96).

An observation that I think is pertinent in understanding my positionality in this research is the generational and cultural divide between participants and myself. The age factor is an important aspect of a generational and cultural divide. Having been slightly or significantly younger than all participants, I noticed how my age impacted my role as a researcher and interviewer, in interviews with participants. The aspects of age, generation, and cultural divide became more apparent when I directed participants to mental health resources in their local community, in case our interview triggered previous trauma they faced. Most participants responded with uncomfortable body language, short answers, or no answer at all. This question was likely perceived as inappropriate for a younger person to ask an older person in the Bahá'í community.

My outsider and insider status of an ambiguous nature allowed for a "state of flux" in my positionality (Fletcher, 2010, p. 15). In addition to culture, race also impacted my positionality in this case study. If the interviewer had white skin and an Anglophone name, asking questions of this scope may have been more acceptable and welcomed. Participants would be interacting with an identity that is more of an outsider and therefore not breaking agreed upon cultural and generational boundaries. This experience made me reflect on my positionality as a researcher which goes beyond a formal interviewer versus participant relationship but considers diverse demographic factors and layers. 
I also reflected on how my educational institution understands and is culturally informed in their approach to ethics and research. Interestingly, the mental health question that I asked participants was a revision from the Carleton Ethics Board that I was required to ask. This added question was not well-responded to and participants seemed uncomfortable answering the question. This, in turn also made me uncomfortable. When I received this required alteration from the ethics board at Carleton University, I suspected it would be with met with hesitation. The interview question asked, "following this interview, what supports do you have access to in your community?", whereby participants needed clarification around what supports I was referring to, and there was confusion around why they would need supports. This uneasiness on my part transferred to the interviews. As anticipated, when participants responded with confusion or discomfort, I tried to ease the situation by reframing the question in general terms. Even so, many participants still seemed uncomfortable and shared vague responses. For participants that did share details, they pushed back on the question wondering why they would need supports given that they are no longer being persecuted in their new respective countries. In describing this shared experience, one participant shared the contrast of our interview versus her experiences at BIHE (2020).

This interview is not a difficult experience at all. Some of those hardships that we went through, during my last semester BIHE university got under attack from the government and most of the professors were arrested and even my supervisor, my undergrad thesis supervisor got arrested. They had to replace them for me just to make sure I had a supervisor, and as soon as they replaced them that person also got arrested and then the third person got arrested. It kind of made to feel that I'm the reason. 
This participant did not understand how our interview together would require mental health resources or supports as it was so far removed from chaos, and they are in a more stable and safer situation now. The required change by the ethics board intended to protect the well-being of participants in case interviews were triggering. Although the revision was an effort to improve this study, I see it as culturally uninformed and inappropriate for the cultural context of my research. The required change did not consider the cultural differences within the setting of an educational institution imposed on a population that was different from their own. This revision also made assumptions on the demographic being studied without engaging in discourse. Culturally uninformed practices from an institution in this case impacted the positionality of the researcher and reflected onto the research itself.

My positionality as a researcher also played a significant role in the recruitment of participants. I had the advantage of being aware of community institutions that exist and have direct access to networks affiliated with BIHE and the Bahá'í community. This allowed for more ease to publicise this study and share the need for participants. The advantage and access that I had, allowed for recruitment of participants to be far easier than it would be for a researcher that was unaware of, and disconnected from Bahá'í community institutions. Additionally, due to the generational persecution that Iranian Bahá'ís have faced, and the fact that I have an identifiable Iranian name, potential participants would likely be distrusting of my intentions and might suspect involvement with the Iranian government. Had there not been formal support from Bahá'i community institutions and disclosure of my faith, it is likely that participants would have been ambivalent or fearful to participate. Nevertheless, due to my connection to the Bahá'í community, a sense of automatic and reflexive trust was established, and I was able to recruit participants with ease. 
Lastly, the tools I gained in previous courses informed my positionality and methodology within this case study. At a graduate level, this included courses on legal methods and social inquiry focusing on methodology in legal research. At an undergraduate level, this has included courses in research methods in psychology as well as statistical methods. I have also completed educational psychology practical courses in skills for interpersonal communication. This background and training refined my skills in responding to sensitive topics and discussions within the interviews conducted.

\subsection{Participants}

A total of $15 \mathrm{BIHE}$ alumni responded to the recruitment initiatives and participated for the entirety of the study. All of them had completed degrees including bachelor and graduate degrees from BIHE. Participation in the study required that all participants currently live in the United States or Canada and speak English fluently. They also needed to have access to a computer, webcam, and internet to participate in interviews. Originally, meeting in-person was an option for participants, but due to the COVID-19 pandemic, and under the guidance of the ethics board of Carleton University, all interviews were solely conducted virtually.

Bahá'ís living in Iran are still under threat and face various forms of persecution today, which emphasised my role in ensuring the safety of participants in this study. To mitigate the vulnerability of participants, all participants were required to be alumni of BIHE and live in Canada or the United States. The names and other identifying information from participants were coded, secured, and kept in confidential and password protected files. I was the only person to have access to identifying information. All identifying data was immediately destroyed following interviews and all coded and unidentifiable data will be destroyed following 2 years after data collection. 
Participants attended and graduated from BIHE between 1994 to 2013. At BIHE, they completed bachelor's degrees in psychology, English language, civil engineering, chemistry, and education. Some of them also completed graduate and professional degrees at BIHE including in public health and business. From the 15 participants in this study, 93 percent received further education following their studies at BIHE. The one participant that had not completed further education had just recently moved to North America within months of the interview conducted and was planning on continuing their education after their English improves. The highest education attainment achieved from this group included four doctorate degrees, eight master's degrees, and three bachelor's degrees. They currently work in a variety of professions including in academia, education, research, clinical psychology, accounting, engineering, and pharmacy. Some participants are also continuing to pursue further education in addition to their advanced degrees. Following their graduation at BIHE, majority of participants had contributed to BIHE through means of administration, teaching assistantships, or as instructors. Many of the participants in this study were currently contributing to the BIHE community from North America in some form and capacity.

\subsection{Community Engagement}

Community engagement was at the forefront of this study to ensure that research endeavours responded to community needs (Ahmed \& Palermo, 2010). Before designing and conducting this study, I prioritized identifying an area of research that could positively impact social change whereby I conducted a preliminary analysis of what area of study could advance the discourse surrounding BIHE. In doing so, I consulted with experts including human rights lawyer, Dr. Roshan Danesh, and the Director of the Office of Public Affairs for the Bahá'í Community of Canada, Corinne Box. I also consulted with former administrators of BIHE. My 
positionality being within the Bahá'í community impacted my access and ability to engage with the community at hand and recruit participants. This included communication with the above, where there was a sense of automatic trust and opportunity for guidance. In addition, it allowed me to connect with other community initiatives including a journalist from the Education Is Under Fire campaign which requested to share the recruitment poster of the study on their social media channels. The established connections and contacts led to successfully widening the network of participants for recruitment of this study.

\subsection{Recruitment}

Recruitment took place in three ways. The first being email invitations sent out to a number of Local Spiritual Assemblies in North America. The email invitation to Local Spiritual Assemblies is included as Appendix E. A Local Spiritual Assembly in the Bahá'í community is an elected body made up of nine members in local communities that help guide and organize a specific locality and communicate with community members in their locality. These email invitations requested Local Spiritual Assemblies to share the email invitation with their community members. These kinds of requests are not unusual, whereby requests are often made to Local Spiritual Assemblies to share announcements, events, and community needs with community members. Some of the Local Spiritual Assemblies distributed a recruitment flyer to community members and some requested communication and approval from the national body of the Bahá'í community in their respective countries, known as the National Spiritual Assembly. Communication and transparency regarding this case study was made clear to national organization bodies as well as public affairs offices in the United States and Canada. Both National Spiritual Assemblies responded with their support and encouragement for this project. 
The second method of recruitment of participants involved contacting the Director of Government Relations for the Office of Public Affairs for the Bahá'ís of Canada, asking that they share the invitation with alumni that attended BIHE. This connection was lucrative as it connected this case study with a former administrator for BIHE living in Canada who shared the recruitment poster with alumni that were eligible to participate in the study.

The third recruitment method, the most effective, was snowballing. Participants knew of other potential participants and shared my contact information and the recruitment poster with them. The majority of participants were recruited this way. Although many participants were referred from previous participants, to maintain confidentiality, I did not divulge or confirm previous participants identifiable information and involvement.

When participants contacted the email address on the recruitment poster to participate in the study, I ensured that they met the eligibility requirements before formally inviting them to join the study and scheduling an interview with them. If invited, they received a letter of introduction and an email invitation as well as consent forms which can be found at Appendix D and Appendix E and Appendix F. In addition, I also answered any questions or concerns that potential participants had beforehand via email. All three methods of recruitment allowed for the preliminary goal of interviewing 15 participants.

\subsection{Data Collection}

Using a qualitative methodological approach, this study employed interview and survey methods. A copy of interview questions and surveys can be found in Appendix A and Appendix B. Participants completed written consent forms and provided oral consent to be recorded prior to interviews starting. These forms can be found in Appendices $\mathrm{C}$ through $\mathrm{E}$. Interviews were not 
conducted without prior informed written and informed verbal consent. Each interview took place in a single interview session, and all were transcribed by me, the principal investigator.

Originally, interviews were approved to take place both online and in person. This would have been possible if participants resided in the Ottawa, Canada vicinity area. Due to the COVID-19 pandemic and changes in requirements from the Carleton Ethics Board, all interviews took place online. Entirely virtual interviews were an unexpected adjustment to this study. Roberts et al. (2021) discuss some of the practical challenges of virtual qualitative research in the COVID-19 era. In their study they identified the current lack of practical and ethical considerations in design of and engagement of virtual qualitative research. Their findings suggest that engagement in virtual qualitative research during the covid-19 pandemic requires purposeful and thoughtful analysis around methodological challenges as well as ethical and equity-oriented questions. I began conducting interviews in April 2020 at the beginning and arguably the most chaotic time of the pandemic in Canada. At that time, swift necessary adjustments were made, without contemplation on the implications and impact of the pandemic on the qualitative interviews. Although a majority would have taken place online due to geographic distance regardless, there may have also been an undertone of chaos with the element of the unknown of a global pandemic. Participants may have been impacted directly by the pandemic while participating in virtual interviews, which in turn could have affected their responses. Interviews that would have taken place in person if it were not for the pandemic, forfeited the opportunity to have a face-to-face interview. Non-verbal body language and cues could have been better detected and provided more depth, direction, and quality to qualitative interactions had interviews been in person. 
Interviews were conducted via encrypted Skype video calls. The interviews were audio recorded on a mobile phone. All recordings were securely transferred to a password-protected computer for transcription. Interviews and transcriptions were coded anonymously so that participants' identification remain confidential. Interviews were semi-structured and had a mix of close-ended and open-ended questions. The interviews began with closed-ended questions to learn about the participants' field of study, further education achieved, and their current field. This was followed with open ended questions on their experience at BIHE, and how they understand resiliency. More in-depth questions followed to learn about their challenges, experiences, milestones, and insights.

Surveys asked participants many similar questions as the interviews and allowed for further validity of data collected. Participants received surveys as a word document which they filled out and emailed back to the principal investigator's university affiliated email address. The data collected from the interviews and surveys allowed for a robust analysis of the data and further theoretical analysis.

\subsection{Data Analysis}

Following the transcriptions of all 15 interviews, as well as the collection of all 15 surveys the data analysis phase of the study began. Due to the number of participants, and qualitative nature of the semi-structured open-ended interviews, thematic analysis of qualitative research data was conducted. From each question asked in the interview, themes were identified and coded in responses. Utilizing different colours for each theme, emerging themes were categorized for each question. Coding was used as an aid for the researcher in understanding prevalent themes and understanding participants perspectives.

\section{$2.9 \quad$ Limitations}


The main limitation of this case study was the small sample size of 15 participants representing a population with thousands. A larger sample size would be more representative in learning about the experience of BIHE alumni. This would increase the validity of the data and implications of this research. Additionally, participants from this case study were limited to residing only in Canada or the United States. Learning about the experience of participants that reside in other countries other than the US and Canada would be more representative of alumnus that have left Iran. For a more representative sample of all BIHE alumni, ideally participants would be comprised of alumni outside and inside of Iran. However, in order to protect the safety and of Bahá'ís living in Iran and ensuring that they are not further vulnerable to violence, this is likely not possible in the foreseeable future.

Additionally, this study lacked comparative data to fully understand if the experience of these participants is unique. Comparative data of other Iranian immigrants that had graduated from public educational institutions and had also immigrated to the US or Canada could have provided further context to the results of the participants that I interviewed. Other comparative data possibilities could have been data on other religious minority groups that have also faced systematic oppression.

In addition, participants could have also had volunteer bias whereby they volunteered to partake in the case study and intrinsically have different characteristics from the general population of interest. Self-selected volunteers in the case could have been individuals who viewed themselves as resilient and were interested to participate in the study perhaps excluding BIHE alumni who may have not felt resilient and therefore were not interested in participating. Similarly, response bias as well as social desirability bias may have been factors that also limited the findings of this research. Demand characteristics could have led to participants forming an 
interpretation of the purpose of this case study and subconsciously changing their responses to fit their interpretation of what their anticipated correct and desired outcomes are.

\subsection{Summary}

This chapter outlined the research methodology used in this case study. An in-depth discussion of the research design, positionality, study participants, community engagement, recruitment methods, data collection, data analysis, and limitations were thoroughly explored. These aspects help informed the complexity of this case study and inform the validity of this

research. The methods used provided a foundation in exploring concepts of resiliency among BIHE students. 


\section{Chapter 3: Theoretical Framework of Resiliency}

\subsection{Introduction}

Understanding resiliency theoretically is significant in understanding the journey of Bahá'ís in Iran that have faced persecution and attended the underground university. Participants understood their adversity as an oppressed minority to be at the root of their resiliency. The concept of resiliency itself is grounded in the reflection of overcoming adversity. Researchers such as Holmes, et al., 2016, and Cheng, \& Mallinckrodt (2015) have observed a connection between adverse oppression and negative outcomes. In contrast, other researchers such as Karlberg (2010) and Javaheri (2018) and theorist Viktor Frankl (1985) have questioned this connection and suggest that negative outcomes to adverse events are not universal. My thesis is expanding what these researchers have not considered in understanding resiliency, specifically within a context of intergenerational oppression. In conditions of intergenerational oppression, traditional resiliency theories are not necessarily intergenerationally informed. This piece seeks to contribute to a theoretical definition of resiliency which accounts for intergenerational oppression.

Learning about specific factors that distinguish adversity leading to negative outcomes versus positive outcomes, is a significant area of study. The implications of this difference can have a powerful impact on individuals and communities facing hardship. Resiliency has been defined through a number of lenses with varying definitions. Advancing the theoretical framework of resiliency, specific to persecuted minority groups that have faced long-term oppression, can contextualize theory pertaining to resiliency and oppression and reach a broader audience. Understanding resiliency in the context of intergenerational oppression can be useful 
for policymakers and justice seeking groups to incentivize and guide communities to have positive outcomes.

In this chapter I seek to explore how resiliency is defined theoretically among participants in this case study. Based on the theoretical discussion and findings from this study, within the context of intergenerational oppression, I define resiliency as a socially embedded process whereby the individual interacts with a model and culture of resiliency from the community. The socially embedded nature of resiliency could be applied theoretically to intergenerational justice seeking groups that have faced oppression in other contexts. Themes which participants also defined as integral to their definitions of resiliency in the context of BIHE included constructively acting as a tool of resistance, building capacity within the individual and resources within the community, propelling the individual and the community forward and improving their circumstances, and seeking justice through non-violent means. In the context of BIHE, Affolter (2007) discusses how BIHE as a case study can contribute to overcoming oppression among other minority groups:

BIHE contributes to this discussion as a case study on how to cope, survive, and thrive in discriminatory sociopolitical circumstances. Even for minorities functioning in more "friendly" circumstances, BIHE provides "lessons learned" on how to create and mobilize social spaces for nurturing youth empowerment, participatory learning, positive identity development, social cohesion, and community pride. BIHE illustrates how community-owned institutes put communities in charge of themselves. They challenge communities to draw from their own resources and talents. They are venues for capacity development and social engagement. They nurture positive connection and self- 
transcendence through community service. They have the potential of becoming the heartbeat of community systems. (p. 76)

The study of most effectively building resiliency and learning about people who embrace resiliency is interdisciplinary and intertwines a variety of disciplines including, but not exclusive to, psychology, political theory, social work, and the law. In the context of this study, I am interested in learning about how participants understood and defined the process and quality of resiliency based on their experiences as students at BIHE, where they are actively responding to persecution because of their religious identity.

This study shows that groups may have different views on what resiliency means and how it can function, and the impact of these findings may be applied broadly. Understanding resiliency theory and how it interacts with the theoretical framework of this study provided a conceptual framework to better understand resiliency among this specific population. In short, I found that participants understood their experience at BIHE and living as an oppressed minority group in Iran to provide them with resiliency.

In this chapter, I will discuss relevant theories including the most common definitions of resiliency. The theories I will discuss are resiliency theory, compensatory model, non-violence theory, constructive resiliency, constructive resistance, and community resiliency. I will demonstrate how these models align and resonate with the data from this study and to what extent they are contradictory and not applicable on a theoretical level. I will further demonstrate how common definitions of resiliency are not fully appropriate and do not fully pertain to this case study. The participants in this study point to important and interesting deficiencies in how resiliency is understood and defined. I will provide feedback on the extent of how some 
definitions are limited in relations to this study and population and what theoretical frameworks fully depict the results from this study.

In addition to the theoretical approaches discussed, I also considered discussing educational theory in understanding intrinsic versus extrinsic values in depth and how it relates to this case study. Although the context of this study on BIHE is within an educational institution, educational theory is too simplistic in the way that it frames resiliency, and I am working in a much more complex multi-generational environment. For this reason, I will not include it in this theoretical chapter. For similar reasons, I am also excluding motivational theory from this chapter. The multi-generational persecution that Bahá'ís have faced in Iran go beyond productivity and performance which motivational theories prioritize.

This case study builds on the constructive resiliency, and constructive resistance theories. The results of this study are also partially rooted in community resilience, and non-violence theory. Resiliency theory and the compensatory model will be further discussed in how they did not sufficiently address resiliency within the context of this minority group. Resiliency has been historically examined through specific lenses that have not necessarily considered an intergenerational group but rather the individual experience. This approach to resiliency is irrelevant to the participants in this study, as the group dynamic and socially embedded nature was at the core of how participants understood resiliency.

\subsection{Resiliency Theory}

In this case study on resiliency, I distinguish between adversity as a result of an emergency of circumstances, versus adversity within long-term contexts. In contexts of hardship, has the adverse event been intergenerational and long term or an isolated short-term trauma? Bonanno and Diminich (2013) categorize patterns of adversity into chronic and acute categories 
and in this case, the Bahá'ís in Iran would fall under a chronic pattern of adversity. The alumni in this study that attended the BIHE underground university did so as a result of their membership to the Bahá'í community. Bahá'ís in Iran have faced this chronic adversity and pervasive patterns which falls under the categories which Bonanno and Diminich (2013) describe. Bahá'ís in Iran have been subjugated and denigrated and their lack of access to education is one tool of persecution that has been experienced intergenerationally and chronically. This specific adversity is an important consideration in this study and understanding resiliency.

Luthar (2006) described “positive adaptation” (p. 6) as a central feature of resiliency in response to adversity or hardship. Positive adaptation is a vague concept that does not specify the degree and the extent of adaptation that an individual and community experiences. Resiliency has also been commonly defined "as the ability to return to one's original functioning following exposure to a stressful or traumatic event" (Tummala-Narra, 2007, p. 34) and as "the ability to bounce back from adversity, frustration, and misfortune" (Ledesma, 2014, p. 6). The "bounce back" (Ledesma, 2014, p. 6) suggests an act of rebounding back to a previous state. At no time throughout any of the 15 interviews that took place did any participant indicate that BIHE would help them reverse to a previous normality. This language implies that although an individual may have taken two steps back in response to a hardship, resiliency means that they would take two steps forward, thereby being back to where they started, with little damage or repercussions. Although this is meaningful and noteworthy, it does not align with what I observed in my case study from the alumni I interviewed from BIHE.

The vagueness of the term "adaptation" (Luthar, 2006, p. 6) and "positive" (Luthar, 2006, p. 6) does not specify the features of positivity or the extent of adaptation. The idea that one bounces back to a previous baseline, or positively adapts, is what differs from my study 
theoretically. I was searching for a theoretical framework that understands resiliency as a force that goes beyond a baseline trajectory and propels individuals and communities forward to an unknown degree, that would not have existed without the adversities experienced. Participants in my study understood resiliency as a tool that propelled them in their achievements, personal attributes, and contributions to their community which they categorized as resiliency. This differs from "bounce back" definition of resiliency (Ledesma, 2014, p. 6) or "positive adaptation" (Luthar, 2006, p. 6), and brought questions of what theoretical grounding would better align with how my participants understood and experienced resiliency. Participants in this study understood resiliency as not having defined or restrictive systematic barriers, but instead a force for propelling forward, which directly contradicts Luthar's (2006) and Bonanno and Diminich's (2013) views and definition of resiliency.

\subsection{Compensatory Model of Resiliency}

Some fundamental aspects of the compensatory model are applicable to this study. The compensatory model understands the process of resiliency as a result of "determination and perseverance" (Ungar, 2004, p. 349). This specific aspect of the compensatory model aligns with how participants understood and defined resiliency. When the study participants were asked to define what resiliency means to them, 87 percent of them defined resiliency as perseverance, steadfastness, and determination. Therefore, perseverance and determination are parallels in this study and in the compensatory model. My definition of resiliency based on the data set resonates with this specific aspect of the compensatory model.

However, this model shares similar limitations as the previously discussed resiliency theoretical model. The compensatory model also understands "resilience as a factor that neutralizes exposures to risk" (Ledesma, 2014, p. 2). Whereby in both approaches, the outcome 
and result of resiliency does not go beyond "neutralizing exposure to risk" (Ledesma, 2014, p. 2). In this case study on BIHE, participants defined resiliency as a force that triggers further advancement and growth, which goes beyond neutralizing a situation. Due to this discrepancy, there is a lack of full compatibility of the compensatory model and how it relates to this study. The compensatory model focuses on "neutralizing exposure to risk" (Ledesma, 2014) rather than acknowledging advancing and propelling capabilities.

Some features of the compensatory model relate to this study and with how I understand and define resiliency. The compensatory model identifies the factors of "determination and perseverance" (Ungar, 2004, p. 349) as resiliency, which is directly aligned with how majority of participants in this study defined resiliency. Conversely, this model is not fully applicable to this study as it is limited in how it understands the potential and impact of resiliency. Although the compensatory model aligns with building individual qualities and capacities, it does not fully encompass how participants defined resiliency. The compensatory model uses language which focuses on neutralizing risk, rather than exerting further potential, and does not consider elements beyond the individual.

\subsection{Community Resiliency Theory}

Community resiliency was a main factor in my study in how participants understood the root of their accomplishments and achievements, regardless of what barriers they faced. According to the Communities Advancing Resiliency Toolkit (CART), community resiliency is defined as "the ability of community members to take deliberate, purposeful, and collective action to alleviate the detrimental effects of an adverse event" (Pfefferbaum, et al., 2013, p. 251). Furthermore, Patel, et al., (2017) conducted a systematic literature review examining 62 publications on community resiliency. Some of the most common definitions and themes 
included local knowledge, community networks and relationships, communication, health, governance/leadership, resources, economic investment, preparedness, mental outlook, hope, and adaptability. The combination of these definitions within the context of BIHE resonate with many of the participants in this study that highlights community networks and relationships as a main factor for their resiliency. In addition, when participants were asked what message or insight they would want to share with other minority groups that are also being oppressed, all participants shared and urged hopefulness. Patel et al., (2017) identified hope as a factor and theme for community resiliency which could be a strong factor that allowed for BIHE students to persevere.

A study by Patel and Gleason (2018) examined the association of social cohesion and community resilience in two vulnerable communities in Port au Prince, Haiti. The results of their study demonstrated an association of a higher resilience score with a higher social cohesion score. They found that community resilience showed a statistical association between the two areas, hence contributing to the literature and argument of how social cohesion contributes to personal resiliency.

Van Breda (2018) discusses how Bottrell's (2009) highlighted the emphasis of family relations, social structures, education, and culture as the "most powerful resilience resources" (Van Breda, 2018, p. 9). Focusing on the social environment, instead of solely on the individual's resiliency, can have a greater impact on the individual and community. Similarly, for BIHE students, the sense of community and social environment allowed them to perceive themselves as resilient individuals. A community-oriented nature is the foundation of BIHE and overlaps with Van Breda and Bottrell's “most powerful resilience resources” description. 
The community-oriented resources Bottrel (2009) describes and the definitions of community resiliency Patel et al., (2017) discusses, share parallels with participants' responses in part from this case study on BIHE alumnus. Community resiliency was demonstrated in this case study in how participants understood their own success and their own definitions of resiliency. Participants identified their resiliency using a community-oriented lens; BIHE provided a sense of community for a marginalized group. They understood their success in terms of their community and the sacrifices of the community. They particularly highlighted the dedication and sacrifice of members of the Bahá'í community within Iran, alumnus who continued to teach upon graduation, and the advocacy from the international Bahá'í community outside of Iran. This strong sense of community both within and outside Iran, within the BIHE community and from outside the school was a motivating factor, and where they discovered the root of their resiliency. As stated, there are many relevant aspects of community resiliency in how it is portrayed in this study. Community resiliency helps define part of the definition and understanding of how this study views resiliency. While this study is grounded in a community resiliency framework, community resiliency is just one aspect whereas this study examines and integrates several aspects into the definition of a socially embedded process, which includes the individual.

Community resiliency deeply aligned with how participants understood and defined resiliency in this case. This case study found the factors they attributed to their outcomes, and experience was a socially embedded process which interacts with their community. Although community resiliency is integrated into how participants understood resiliency, it is not allencompassing and only touches on a specific aspect of their comprehension of resiliency. Beyond the community-oriented aspects of their experience and outcomes, participants discussed 
other significant elements contributing to their resiliency. This aspect aligns with the interactive way participants understood resiliency, where the individual and the community are intertwined in the development and growth.

\subsection{Non-violence Theory}

In this case study participants discussed the significance and profound nature of their resiliency as a non-violent act. Therefore, examining and exploring how non-violence theory relates to this case study is pertinent. This section will discuss non-violence theory in more depth and in how it relates to this study.

According to Holmes (1971), non-violence theory is based on the assumption that nonviolence has a significant degree of power and force. Holmes (1971) makes an important distinction between nonviolence, nonresistance, and passive resistance. Nonviolence being direct action through a nonviolent approach, nonresistance being willingly suffering without action, and passive resistance being a form of noncooperation. He argues that violence is not justified based on a premise that it is the only effective means of preventing violence. In the case of the Bahá'í students attending BIHE, they would likely align with nonviolence in which Holmes describes and not with nonresistance nor passive resistance.

From an anthropological lens of non-violence, Patfoort's (1987) conceptual framework of nonviolence discusses two main principles of balancing personal power with a lack of violence. According to Patfoort (1987), personal power emphasizes a lack of violence against oneself which is a stance of power and strength and avoids passivity. The root and foundation of violence is based on a hierarchal power relationship and that nonviolent action switches from a hierarchal power dynamic to a more restorative model. When an individual's instinct of protection is triggered, the individual is inclined to respond. Nonviolence is consciously avoiding 
aggression, and instead assertive in a nonviolent approach. Some of the necessary skills which Patfoort (1987) identifies in order to be nonviolent include the ability to focus their anger positively as well as the capacity to develop and adhere to strategies of solidarity, unity, collaboration, cooperation, and creativity. This theory has been applied to various contexts including ethnic conflict in East Congo, Rwanda, and Kosovo. Many of the approaches which Patfoort (1987) discusses resonated with many participants in this case study. When participants were asked what message, they would share with other minority groups that are oppressed or persecuted, many of their responses shared messages of encouragement with the similar skill set that Patfoort (1987) describes.

Kool's (1993) theory of nonviolence discusses how individuals that act non-violently are attempts in achieving social harmony through high moral behaviour. Non-violence allows a shift in power, whereby power is taken away from the violent adversaries and given to the individuals that act non-violently. This is achieved by affecting the conscience and the hearts of violent adversaries. This component of nonviolence is considered a tool in how nonviolence is a form of power and has the capacity to influence and change behaviour. In relation to this case study, perhaps the act of obtaining education through non-violent means may shift the hearts and conscience of oppressors. Thereby shifting power in a strenuous environment from violence persecutors to religious minorities seeking education. This approach to non-violence can impact communities and allow for the most marginalized groups to hold power they previously did not have access to.

Building on Kool's theory (1993), Sharp (1959) discusses nonviolence as a political theory whereby nonviolent action is defined as "A technique of action in conflicts in which participants conduct the struggle by doing - or refusing to do - certain acts without using 
physical violence." (Mayton, 2008, p. 48). In the case of BIHE in Iran, this would pertain to participants actively doing certain acts without using physical violence as a "technique of action" (Mayton, 2008, p. 48). Similarly, to Kool's theory of nonviolence, Sharp (1973) discusses this shift in power from violent adversaries to increasing one's own power through nonviolent acts. This is based on individuals refusing to do what they are being told. They decrease the power from their adversaries and increase their own power through nonviolent acts. Sharp (1973) classifies three nonviolent political responses including nonviolent protest and persuasion, nonviolent noncooperation, and nonviolent intervention. Nonviolent intervention is based upon actions which disrupt a system and could be a development of a parallel system. Nonviolent intervention is understood to be the most powerful and impactful method out of the three classifications of nonviolent political action. The response of the Bahá'ís in Iran can be categorized under Sharp's most powerful method, nonviolent intervention. They are channeling their acts of nonviolence towards developing a new system as Sharp describes. When public higher education was not accessible to them, they created a new system.

The different perspectives of non-violence theory coincide with the approach of how BIHE participants understand their response to opposing oppression. BIHE participants understood their resiliency as a function of the non-violent approach they took to violence. This theoretical standpoint is integrated into the definition of resiliency that this study demonstrates. Although non-violence theory is not a theory of resiliency, it is a significant approach in how participants understood resiliency, whereby it is ingrained in the process of seeking justice through non-violent means.

\subsection{Constructive Resistance}


Constructive resistance also plays an important theoretical role in framing how participants in my study understood resiliency and the impact on their lives. Participants understood their resiliency as a form of resistance to the oppressor while constructively building resources within the individual and the community. Sørensen (2016) describes constructive resistance as "initiatives in which people start to build the society they desire independently of the dominant structures already in place" (p. 49). The participants I interviewed did not consider responding to the oppression they faced through violence. Instead, they held values such as collaboration, sacrifice, and rigour, that were dedicated to building an independent structure to serve their practical needs while simultaneously constructively resisting oppressive powers. Individuals and communities that are constructively resisting "imagine that things can be different, they experiment through trial and error, they change practices and norms, and they share their experiences with others" (Sørensen, 2016, p. 71). This attitude and approach that Sørensen (2016) describes of "creating an alternative" (p. 71) solution or structure aligns with the approach and values of the participants that I interviewed.

Koefoed (2017) further discusses constructive resistance within the context of examining Kurdish cultural and linguistic oppression in Turkey's Northern Kurdish region. Repressive cultural assimilation policies towards individuals who identify as Kurdish have occurred through legal restrictions on educational institutions. One tactic in particular is the restriction of the usage of the Kurdish language in educational institutions. An act of constructive resistance by the Kurdish community has been to create parallel primary schools in Kurdistan which reject the nationalist curriculum in Turkish schools. This situation shares a resemblance to Bahá'ís at BIHE, whereby many Kurdish primary schools have been subjugated to enforced closures, arrests of teachers and administrators, and violent attacks. This nonviolent act of creating a new 
educational institution despite oppression shares commonalities with BIHE in Iran. Koefoed (2017) describes the creation of parallel primary schools which teach Kurdish language, culture, and traditions as an act of constructive resistance. Koefoed (2017) discusses the relevance of Sharp's (1959) nonviolent political theory, the creation of parallel structures described as nonviolent intervention, as the most powerful form of nonviolence. Non-violence theory will be discussed in more depth later on in this chapter, however, the theory is relevant at this point in understanding the context of constructive resistance. Constructive resistance in this context is described as rejecting the politics of waiting, and instead reduces the gap in time between resistance and change. Change is established within the resistance itself instead of a faraway goal to be achieved. "By establishing an alternative to these dominant educational structures, the Kurdish movement is engaged in a process of reducing its dependency on the state, and gradually reducing the structural violence embedded in those structures" (Koefoed, 2017, p. 48). This context of constructive resistance in Northern Kurdistan shares a similar pattern in understanding social change and resistance in reducing structural violence among Bahá'í students in Iran.

The creation of parallel structures, such as the case of culturally inclusive primary schools in Northern Kurdistan and the establishment of the BIHE university for Bahá'ís in Iran, demonstrates Sharp's non-violent political theory. Both minority groups established an alternative to dominant educational structures. Consequently, by not accepting defeat, both minority groups have taken power away from the embedded structural violence, as they are not subject to the rejection and exclusion they have faced. These initiatives act as a form of constructive resistance to a dominant structure and oppressor. They reflect constructive resistance theory as they are creating an alternative option and engaging with a structure they desire regardless of the dominant structure and society they live in. 
Constructive resistance encompasses how participants in this study understood the outer and external impact of their endeavours. Participants understood their involvement at BIHE as what Sorenson (2016) describes as an act of "creating an alternative" (p. 71). Constructive resistance within the context of the Kurdish community in Turkey's Northern Kurdish region further demonstrated how constructive resistance is enacted. The Bahá'ís in Iran at BIHE, resembled features of the productive and constructive acts of resistance of the Kurdish community in Turkey. Both educational endeavours strive to advocate for the freedoms and human rights of their community be constructively resisting.

Constructive resistance accurately describes how participants understood their role in relation to the context they lived in, and how they impacted their environment and circumstance. They understood their path to education as an act of resistance to the oppressor, while taking concrete steps towards justice. However, this theory lacks a focus on the individual's journey and inner world. Participants highlighted their character development and refined personal qualities that they received from resistance. The constructive resistance theoretical framework does not include the aspect of individuality, but rather focuses on the more outwardly, tangible features of resistance and progression.

\section{7 Constructive Resiliency}

Constructive resiliency has been described as the act of not succumbing in resignation to the oppressor or taking on the characteristics of the oppressor (Karlberg, 2010). I find constructive resiliency and constructive resistance to more accurately describe how participants perceived resiliency in this study. The constructive resiliency model goes beyond resiliency theory and the compensatory model. Constructive resiliency discusses how building capacity within the individual and the community are beyond being adaptable and flexible, and beyond 
regressing to their baseline trajectory. Although resiliency theory applies to my study in some aspects, it is limited in its applicability. Instead, the data demonstrates the concept of constructive resiliency and is applicable to this case study.

Javaheri (2018) describes constructive resiliency as "a non-adversarial, violence-free, but dynamic approach to creating patterns of social engagement that move away from contention. At the same time, community members are vigorously pursuing every possible legal avenue available to correct and remedy the prevailing injustice" (p. 12). The approach of responding to violence by building a recognized underground university is an example of what Javaheri (2018) is describing. BIHE is a demonstration of nonviolent action through the form of a university whereby the community can still pursue advancement. Over half of the participants in my study defined resiliency as a form of building capacity to contribute to moving forward, constructively, in a non-violent manner. Participants resonated with Javaheri's and Karlberg's definitions of resiliency as a constructive model that is practically building and advancing within the individual as well as building their community. In the context of Bahá'ís in Iran, Kazemzadeh (2019) discusses how constructive resilience impacts individual growth for Bahá'ís as they navigate through persecution:

Constructive resilience provides a framework for participants to navigate through their experience. It serves as a sense-making mechanism for the participants to understand their own suffering and why they should respond to oppression in a unified manner, providing a sense of purpose to their own behavior and those of the other Bahá'is.

The constructive resiliency model is useful and applicable to how this study demonstrates and defines resiliency. The constructive resiliency model acknowledges the interacting contributions 
from the individual and community. Constructive resiliency does not accept victimization or surrendering to the oppressor, and also does not pertain to mimicking the tactics of the oppressor. This understanding is demonstrated because participants expressed that they would not accept being unable to attain an education. Further, the constructive resiliency model also outlines the non-violent, non-adversarial, approach to violence while still actively pursuing possible legal measures of justice. The constructive resiliency model coincides with how participants in this study on BIHE alumnus understood resiliency and reflects their process of engagement.

\subsection{Definitions and Implications}

Based on the theoretical discussion and findings from this study, I define resiliency as a socially embedded process that acts as an institutional model of resiliency to its members and creates a culture of resiliency. This definition could be applied theoretically to other intergenerational justice seeking groups that have faced oppression in different contexts. This process propels both connected constituents forward, and mutually aids the individual and the community, despite significant barriers. Therefore the socially embedded nature of resiliency is intertwined with the community and the individual. Participants identified the following themes as being integral to how they define resiliency in their context as Bahá'ís from Iran and BIHE alumni: constructively acts as a form of resistance to oppression and results in improved circumstances, qualities of advanced character development and greater material outcomes, building capacity within the individual and resources within the community, propelling the individual and the community forward without remaining a victim to systematic barriers, improving their circumstances, and seeking justice through non-violent means.

The socially embedded nature of resiliency is significant as it interacts with the community, whereby the community and the individual mutually build off one another and 
become stronger. Furthermore, the socially embedded nature of resiliency could implicitly demand an element of accountability, potentially leading to improvement among participants and higher outcomes among individuals and the BIHE community.

Within this description, non-violence theory, constructive resiliency, constructive resistance, and community resiliency are embedded within this study's definition of resiliency. In particular, constructive resiliency best encompasses how participants understood their experienced resiliency. The theoretical contribution of this study emphasizes the need to reflect a socially embedded nature in resiliency theory. This study does not support a vision of resilience that includes conceptions of how traditional resiliency theory, and the compensatory model understand resiliency. Unlike these models, this study does not define resiliency with the barriers involved in bouncing back, or neutralizing oppression. This definition is particularly different from the common definition of resiliency theory as it understands resiliency as something that builds beyond the previous status quo. It integrates the close relationship of the community and the individual in achieving resiliency, while improving their practical circumstances and attaining justice. 


\section{Chapter 4: Results}

\subsection{Introduction}

In this section I will attempt to parse out the definition and themes of resiliency identified by participants in this study. A main insight gained in this thesis is that many definitions of resiliency are limited, perhaps due to the context it has traditionally been studied in. When I consider resiliency in the context of BIHE alumni residing in North America and examined resiliency vis-a-vis their experience, traditional resiliency theories did not capture their experience because it was so tied to the institution. Instead, I define resiliency and the formation of resiliency in two ways: one being through the institution whereby BIHE models resiliency itself. For example, when school websites were blocked to prevent access to educational materials, BIHE had new websites and resources to access ready for students. The institution demonstrates creativity in how to survive and thrive under conditions of extreme hardship. Students are not just facing oppression in their involvement at BIHE but in their everyday lives, where they are able to take this culture of resiliency with them. This could be considered a model of resiliency itself, whereby students are pupils under a model of resiliency and learning under a culture of resiliency.

Themes that emerged from participants when describing resiliency included: a socially embedded process that constructively acts as a tool of resistance, while building capacity within the individual and resources within the community, which improves circumstances of individuals and communities and propels them forward through non-violent means of seeking justice. The definition participants discussed relates to a unique theoretical aspect of this study: the socially embeddedness of resiliency. The socially embedded nature of resiliency is intertwined with the community and the individual, which fosters and fuels the different components of resiliency. 
Standard theories do not fully appreciate the embedded nature of the development of resiliency both as a process and as a quality.

In this chapter, results from the qualitative interviews and surveys are examined and presented in detail through a theoretical lens. I will share how the data is relevant to key themes. Throughout this section, I will utilize vignettes from participants. Utilizing resiliency theory, the compensatory model, non-violence theory, community resiliency, constructive resistance, and constructive resiliency, I will demonstrate how participants understood resiliency. I will explore these theories in understanding the following aspects of the definition I propose here: a socially embedded process, advancing resources within the community, building capacity and qualities within the individual, tools of resistance, improving outcomes and circumstance, the lack of barriers and propelled outcomes, a non-violent approach, and lastly, means of seeking of justice. This research highlights the propelling nature of participants that are not subject to systematic barriers due to what they define as resiliency due to the socially embedded nature of their experience. Participants understood that BIHE was an institutional model of resiliency that students could mimic in their own functioning. This process and definition can contribute to more general discourses on resiliency, oppression, and resistance.

\subsection{Socially-embedded Process}

A vast majority of participants understood resiliency as an embedded social process where the interconnectedness of the community and the individual foster and fuel resiliency. The relationship between access to education and resiliency is a mutual relationship that acts as a cycle and nourishes one another. BIHE itself is a model of resistance and also creates a culture of resiliency at its institution. BIHE teaches and fosters resiliency as a community endeavour. A major critique of mainstream definitions are that they do not fully consider the importance and 
interaction of the community and the individual. The individual and the community have a symbiotic relationship to each other; students find comfort, are protected, and challenged by their studies but also deeply ingrained with the notion that they will prosper regardless of obstacles.

The existence and positive impact of this relationship was demonstrated in interviews whereby 87 percent of participants described the interconnectedness of the community and the individual as what has allowed them to achieve educational outcomes and resiliency. One participant discussed this strongly tied connection in the following excerpt (2020):

My experience at BIHE was intertwined. The education was intertwined with resiliency. Education was the act of resiliency by the mere participation in that university we were in. It was an act of resilience. Moreover, by studying in that university and by going through that experience, we learned to be more resilient. We learned how to cope with the fact that each session of our class we could have been arrested. The resiliency developed in me impacted my education. I learned to cope through difficulties. Resiliency impacted my education and my life even after BIHE. This participant identified how education and resiliency were intertwined and embedded. The social embeddedness of resiliency had long term implications for this participant outside of the period they attended BIHE. They were able to utilize the skills and experiences they gained at BIHE to cope with different difficulties in life. The model of resiliency BIHE offered as a community institution impacted the resiliency of individuals while at BIHE and in the long term. BIHE's functioning as an institution taught students how to be resilient. The aspects of resiliency outlined such as developing capacities and qualities within the individual and advancing resources within the community, align with the socially embedded nature of how this case study approaches resiliency. The social embedded structure at BIHE impacted future educational 
achievements and thereby individual resiliency, while also interacting and relying on community structures. The relationship between the community and the individual for developing resiliency has implications for other oppressive contexts. This relationship suggests that a communityoriented institution and structure, closely binds with the individuals within the community, and together they build a collaborative momentum of growth.

The implication of a socially embedded relationship raises questions of how a structure in the form of an educational institution, in an oppressive setting, impacts the resiliency of individuals. The socially embedded nature of BIHE could be described as unique in comparison to university models in North America. What distinguishes the resiliency of BIHE as an institution and BIHE graduates, versus a public university in North America and their alumni? While I do not have data on a North American setting my initial reflection is that the circumstances of BIHE as an underground institution substantially differs from North American higher education institutions in functioning, operation, and experienced challenges. Participants from BIHE viewed their educational experience at BIHE as being closely intertwined and interwoven with the individual and the community, resulting in their resiliency. This relationship between the individual and the community was demonstrated when participants were asked why they believe BIHE has been able to survive despite oppression. Over half of the participants attributed BIHE's continuous existence and survival to BIHE alumni contributing their time to BIHE, emphasizing contribution to the community structure. Perhaps the model in which North American institutions operate focuses more on the student passively receiving services and the university being responsible to offer services. The two are related and connected but not intertwined with one another. Contrastingly, BIHE students placed importance on the socially embeddedness of BIHE which allows for BIHE as an institution to be resilient. In turn, this 
model of resiliency from the community and institution became embedded into the disposition of the individual. To understand the ties within the individual and the community I will explore each aspect in further depth.

\subsection{Advancing Resources within the Community}

As discussed, participants defined resiliency as being socially embedded within the community and the individual. Specifically examining how the community and the individual contributes to the socially embedded nature of resiliency, participants defined resiliency as the act of building resources in the community, which in turn impacts individual capacities, acts of resistance, and means of seeking justice. Institutional and community resiliency were at the core of how participants understood resiliency for themselves and how they navigated their situation. This was demonstrated because BIHE as a community institution acted as a model of resiliency and influenced qualities of resiliency within the individual. The model in which the community was able to advance resources and community development on an institutional level, mirrored how participants too saw themselves with similar qualities of resourcefulness and determination.

Regardless of not having access to tangible buildings and a physical structure, participants emphasized the strong sense of community that was integrated into their education. Participants from BIHE viewed their community and the individuals that make up their community as a protective shield preventing them from being a victim of adversity and oppression. This 'protective shield' element of the community is crucial to resiliency as a socially embedded process. Participants I interviewed understood this shield as protecting their inner identity from a victimhood identity.

Alumni shared that BIHE was their sacred, special place and refuge in a society where they are continuously denigrated in so many different areas of their lives. A participant shared 
that without BIHE, the youth of their community would likely have been depressed or suicidal, but the supportive community and existence of BIHE allowed for them to have hope within a state of turmoil. BIHE provides students with a community and opportunity to be uniquely special and have access to a profound path within an oppressive environment.

As previously discussed, BIHE is operated by a volunteer affiliated global faculty and administrative staff of over 955 members and has five faculties consisting of five associate programs, eighteen undergraduate degrees, and fourteen graduate degrees, relying heavily on the collaboration of their community (BIHE, 2021a). The purpose of their volunteer collaboration at BIHE can be understood through Pfefferbaum et al.'s definition of community resiliency in which it is "to alleviate the detrimental effects of an adverse event" (2013, p. 251). This was made evident whereby 93 percent of participants believed that the collaboration and sacrifice from their community was a main factor allowing BIHE to survive despite the oppression faced. One participant who had been imprisoned for their involvement at BIHE, and now holds a $\mathrm{PhD}$ in their respective field, understood their dedication as a means of community resilience. They shared how "through community efforts, systematic community efforts, you can combat oppression much better than an individual effort" (2020). The community-oriented and collaborative nature of the BIHE community allowed for individuals to thrive regardless of chaos and violence. This too, contributes to resiliency as a socially embedded process.

Echoing the community resiliency framework, a vast majority of participants continued to be involved and contribute towards BIHE following their graduation, contributing to the socially embedded nature of BIHE. The dynamic system at BIHE is not one where one party gives and the other party takes. Rather, it is a relationship where all parties practice selfless action regardless of changing circumstances. Participants felt that it was their responsibility to 
contribute to the needs of their BIHE community. As previously discussed, they volunteered their time in a variety of roles as hosts, administrators, teaching assistants, and instructors while living in Iran, or offering services remotely. This included many alumni who volunteered as teaching assistants while balancing their responsibilities pursuing masters or doctorate degrees in North America. One participant in this circumstance reported the responsibility they felt, personal sacrifice, and significance of community collaboration (2020):

I felt that I had to fight for it. I have to be there for it. Ever since I graduated anytime they asked me to do something for BIHE, I will do it. When I started teaching at BIHE 2 years ago, teaching the class I am still currently teaching, I was still a graduate student myself here. I had a lot of work to do but they contacted me that the teacher who was teaching this class cannot teach it anymore...I was reading the email and I had my own pile of papers and books that I have to study in front of me and I thought, okay if you're telling me this, you don't need to beg me, I will do it. This cannot be stopped. Yes, of course I will do it, but thank God I had three teaching assistants who helped me.

This excerpt demonstrates the deep commitment that community members felt towards contributing to the needs of BIHE, regardless of competing responsibilities.

In addition, more than half of participants shared that their education at BIHE brought a sense of purpose, motivation, and resiliency to their community. The theme of motivation participants expressed is similar to a study by Affolter (2007) that examined "Resisting educational exclusion: the Bahá'í Institute of Higher Education in Iran”. These attributes towards a community effort in turn positively impacted its individual members. In addition, when asking participants how education contributed to their resiliency, the most common response among participants was the community's involvement in their education. They understood that their 
community was sacrificing their own safety so that as a young person they could attain

knowledge and a formal degree. Further affirming the socially embedded nature of resiliency, in describing community, participants identified their family members, peers, and Bahá’í community both within Iran and internationally through advocacy, support, and guidance, from outside of Iran. Demonstrating community resiliency, and illustrating the sense of collaboration which impacted student outcomes and success, one student shared the following anecdote (2020):

During my last semester at BIHE, the university went under attack from the government and most of the professors were arrested, including my thesis supervisor who I had been working with all year. They had to replace them just to make sure I had a thesis supervisor. As soon as they replaced them my second thesis supervisor was arrested. Then I was assigned a third supervisor, and they got arrested too...They all chose to be my thesis supervisor voluntarily, but still.

Finally, the student was assigned a fourth thesis supervisor from the collaborative network at BIHE and was able to finish her thesis and graduate. As demonstrated, this student was directly and positively impacted through the resiliency of their community. Had this participant's first thesis supervisor been arrested, and she responded to this hindrance by not completing her studies, she would have succumbed to her oppressor. However, through community resiliency, a total of four thesis supervisors endangered their safety by prioritizing her education above themselves. This excerpt illustrates how collective action that occurred among this religious minority group in Iran responded and overcame adverse generational persecution.

Another observation is that a third of participants also mentioned how their access to education at BIHE impacted their community by reducing stigma of Bahá'ís in Iran, among 
fellow Iranian citizens. Reducing stigma of Bahá'í's within the Iranian community could also be considered a sign and outcome of community resiliency. In addition, it may point to increasing numbers of building a wider community that protects and promotes the rights of Bahá'ís in Iran. BIHE could be a factor in increasing support from the wider Iranian community, to defend BIHE and promote the education of Bahá'ís. This in turn may allow for further collective action, as the collective becomes larger in numbers, whereby directly or indirectly collective action becomes a part of Iranian society as a whole.

Advancing resources within the community is at the forefront of how participants understood resiliency. The impact of a strong and resourceful community allowed for members to thrive and attain an education. They described the sacrifice of their community as the "support system to get through it. They were not helping us with our homework, but they were to help like every family sacrifices for their own children" (2020). Community resiliency is heavily integrated into how participants understood resiliency and grounded into the socially embedded framework of this study. Although fused into how participants understood their resiliency, community resiliency alone is not fully comprehensive in fully describing resiliency among BIHE graduates. In addition to advancing community resources, participants also discussed in detail aspects which focus on the individual as well as purposeful and creative ways of responding to injustice as part of their resiliency.

\subsection{Building Capacity and Qualities in the Individual}

The socially embedded nature of resiliency was closely interwoven with individual growth and qualities. Participants related the strength of community collaboration to the mutual growth of the individual, whereby with both entities present, resiliency was able to exist. The socially embedded framework of the community acted as model for BIHE students where they 
were able to mimic the qualities and approach of BIHE into their own lives. A vast majority of participants shared that their education at BIHE empowered them by contributing to their development of personal qualities and achievements, and thereby allowing them to thrive as individuals. The conceptual framework of building capacity and refining qualities within the individual is coherent with constructive resiliency.

Participants at BIHE understood the individual qualities and accomplishments they gained were due to the propelling nature of resiliency. Some of these qualities gained are under the umbrella of the compensatory model, which defines resiliency as a result of qualities of “determination and perseverance" (Ungar, 2004, p. 349). This definition of resiliency is reflected in this case study, as 87 percent of participants defined resiliency as perseverance, steadfastness, or determination - all personal characteristics that they believed to have been refined due to their experience at BIHE. One participant expressed how they understood the outcome of determination and perseverance (2020): “Although we don't have the privileges that others have, we with persistence, and determination, and we have a positive attitude. With a fighting attitude we can accomplish a lot." They understood how personal characteristics acted as a strong pillar in their resiliency and triumph over oppression, propelling them forward.

Furthermore, two thirds of participants defined resiliency as the capacity to build and contribute to their own lives. These qualities and characteristics also gave participants the tools to detach from a victim mentality to an identity that is characterized by empowerment. Some of the qualities that participants described that they gained included: perseverance, hopefulness, flexibility, high standard of excellence, passion for learning, positivity, and self-motivation. All of these qualities contributed to their advancement and propelling forward as individuals. They 
related the qualities and personal skills that they gained as being transferrable to their professional and personal lives outside of BIHE.

In understanding the impact of resiliency, the constructive resiliency framework includes how individuals are positively impacted and resonates with how participants understood resiliency. Through an approach of social engagement, constructive resiliency is also the rejection of a victimhood identity as an individual or community under harsh conditions and abuse. Thereby nourishing personal character qualities and virtues. Constructive resiliency creates patterns of social engagement that advance and progress rather than contribute to contention (Javaheri, 2018). Participants identified these qualities as part of the individual-based components of their resiliency and how it interacts with their community.

In addition to a variety of qualities and skills, the element of empowerment may explain why 93 percent of participants continued to higher education following their degrees at BIHE. The one individual that had not continued to higher education had just moved to North America a few months prior to our interview together, and was focused on improving their English language skills. Although this case study did not include comparative data, a study from the United States that researched educational attainment among first generation Iranian immigrants found that the percent of those that attained graduate or doctoral degrees was half of the amount if they were male, and a quarter of the amount if they were female, compared to the results of my case study (Bozorgmehr \& Douglas, 2011). Regardless, in reference to the individual, the resiliency of participants has allowed for most participants to continue their education even though their original circumstance did not allow them to access higher education. They understood this route to be unrestrictive and a path in which they were able to propel and advance forward and forge ahead. The impact of access to education has allowed for further 
education to be achieved in their life trajectories. Furthermore, the opportunities granted to participants have potentially allowed for the families and children of BIHE alumni to thrive in an environment that is more financially stable due to achievement in education. The impact of BIHE has a generational impact on the individual lives and families of Bahá'ís.

Coinciding with how the constructive resiliency framework views building individual capacity and qualities, 75 percent of participants defined resiliency as a form of resourcefulness whereby creativity and flexibility contributed to individual abilities. One participant described how their resiliency impacts them in the context of trials and tribulations, more specifically in the unique context of when interviews were conducted for this study, during the COVID-19 pandemic (2020):

When the pandemic happened, my colleagues kept asking me how it impacted me. Well, it's nothing, it didn't impact me much. The changes from the pandemic are not going to last 60 years or 80 years or through generations like for Bahá'ís in Iran. I just do the same thing I was doing 30 years ago back at home, but now I have tools and electronics to do my work, and I don't have to worry about being arrested.

This participant understood how they were able to apply their personal qualities, and skills towards future crisis. This included being able to view a difficult situation like the restriction of the COVID-19 pandemic, with an optimistic attitude and skills of resourcefulness.

Participants understood their resiliency as impacting their own perseverance and determination. 87 percent of participants shared this sentiment in how BIHE impacted their individual life. This view aligns with the compensatory model which understands resiliency as “perseverance and determination” (Ungar, 2004, p. 349). 
The impact of BIHE on individual lives, are the lives which make up the community and are socially embedded in resiliency as a whole. Utilizing BIHE as an institutional model of resiliency, participants were able to extract the qualities and mimic the process of BIHE's response to oppression in their individual approaches. They shared the same determination and perseverance that their institution exemplified. The individuals that are interwoven with the community understood that resiliency is the result of a socially embedded process. This resiliency led to further resiliency through acts of resistance and seeking means of justice, contributing to the cycle and embeddedness of resiliency. Participants understood that BIHE impacted their own capacities, the individual lives of future graduates, and the context in how individual resiliency is closely related to combatting oppression among a minority group.

\subsection{Tools of Resistance}

Participants described their resiliency as an act of resistance and tool in combatting oppression. They understood their education at BIHE as a type of resistance to oppression whereby the educational process at BIHE is part of a greater act of non-violent resistance. The process-based experience of gaining an education and simultaneously resisting oppression allows BIHE alumni to experience a specific type of resiliency, leading to more resilient acts of resistance. This response to oppression is aligned with how participants understood their experience of oppression and their understanding of resiliency. BIHE students described their experience and understanding of resisting oppression as a profound step forward of building and forging ahead regardless of facing turmoil and integral to their resiliency. Nor did participants forfeit their rights and passively accept their circumstance. They did not fight fire with fire by mimicking the strategies of their oppressor, or focus on their oppressor's punishment. Instead, they quietly focused on building a more fitting solution and did not allow themselves to be 
drenched in a victim mentality. Participants valued not having a victimhood identity and demonstrated this by their continuous commitment to their education and future. From the participants that I interviewed, 80 percent have obtained graduate or doctoral degrees.

Additionally, this statistic does not include some of the participants who have just recently left Iran and are planning on pursuing further education. Participants viewed continuing to attain education as resistance against their oppressor. They have devoted their energy into constructively building, rather than solely being attached to fighting contention. One participant describes this phenomenon where they distinguished their understanding of pure resistance versus resilience in the context of the BIHE in the following anecdote:

When there is oppression, they will start resisting to the higher power be it government, be it religious leaders. Both sides lose because it's a vortex that sucks both sides in, but not if resilience is emphasized and if it's a goal. Resilience to me means steadfastness with a willingness to thrive, to move up, but resistance is yes steadfastness, standing up for yourself but the destiny will be determined by how your opponent will react. If they go down, you do down with them.

For this participant, oppression is overcome through resistance which is part of their resiliency. This particular form of resisting oppression is not conducted by whatever means possible. Instead, BIHE alumnus define the non-violent means they are willing to undergo in order to achieve desired ends. They understand the productive and conducive nature of responding to violence with constructive resiliency.

Utilizing a constructive resistance framework, the creation of creative responses to injustice is integrated into how participants understood resiliency as a minority group overcoming oppression. Specifically, constructive resistance creates opportunities in the form of 
parallel alternatives in the face of oppression or persecution through non-violent means. The following participant shared in their interview the significance of the establishment of a parallel alternative when discussing how to respond to systematic oppression (2020). This participant raised the question "what are you going to place as justice instead of that injustice in a society?" in describing the existence of BIHE and its resistance to oppression. BIHE students understood that BIHE was the alternative option allowing them to productively and effectively resist oppressive forces.

In conducting data analysis, it became apparent that participants resonated with a constructive resistance approach in responding and overcoming violence as an oppressed minority group. This was demonstrated by 93 percent of participants who understood that their strength and resilience stemmed from being embedded in BIHE as a form of resistance. Participants interpreted this as the main factor in overcoming barriers for themselves but also for other diverse minority groups in an oppressive context. The existence of BIHE as an educational institution was a symbol and act of resistance.

Additionally, 73 percent of participants identified that the parallel alternative of being able to access education through BIHE was the sole reason for their current professional positioning and achievements. Without the existence of BIHE, they believed that they would not have had access to opportunities in their professional and personal lives, including having the means to leave a country where they are systematically persecuted. They understood their attainment of achieving education as individual acts of resistance, reflecting a modelled act of resiliency and resistance of BIHE as an institution. This includes 80 percent of participants who used their BIHE to obtain graduate and professional degrees and saw this attainment as 
resiliency itself resisting external oppression. They understood exceling in their fields as professors, pharmacists, psychologists, researchers, and so on, as profound acts of resistance.

Further, two-thirds of participants defined resiliency as a non-violent form of resistance and the capacity to build and contribute to their own lives and their community. These results are congruent with the construction of novel alternatives within the constructive resistance framework. Resistance was also connected to a sense of empowerment among participants. One participant shared the empowerment they experienced from the unshackling from control and oppression associated with acts of resistance (2020):

For myself, getting expelled from university and thinking some people don't want me to achieve something, and they don't want me to be successful, it empowered me to think I'm going to prove them wrong. You don't want me to study, I'm going to study. You don't want me to be a successful person, I'm going to be a successful person. So, you're going to see you cannot stop me. For me especially at that age that basically empowered me even more instead of making me depressed or something... We saw it as a fight maybe or more of a resilience, if you don't want me to achieve, I will achieve. Every time they put more pressure on BIHE, we got more of that power. I remember the time my supervisor got arrested, I was mad. You don't want us to study, we are going to study harder. I studied even harder after my supervisor got arrested.

The parallel structure and alternative option for this student and other BIHE students allowed for an oppressed community to experience empowerment within their acts of resistance. Participants understood the significance of replacing an injustice with an experience characterized by justice. One participant expressed this specific notion in the following excerpt: "You can combat injustice, but it's one thing to combat injustice, and another thing to place something instead of 
injustice." BIHE students understood the importance of finding a parallel alternative within an unjust system. This view resonates with how constructive resistance approaches oppression and injustice.

Integrating a non-violence theoretical framework, constructive resistance focuses on the on the building of resources and infrastructure of parallel opportunities and structures. Participants expressed this conceptual framework in their interviews and stood under the constructive resistance theoretical umbrella. While this study is heavily grounded in constructive resistance theory, and understands resiliency as an act of resistance, constructive resistance itself does not fully encompass how participants defined resiliency. The full approach and definition which participants describes as resiliency encompasses an act of resistance but also integrates other prominent themes.

The existence and functioning of BIHE as an educational institution is an act, tool, and symbol of resistance in an oppressive environment. The educational attainment and access which participants benefited from were identified as acts of resistance to injustice, and constructive steps towards justice. Resisting injustice through means of developing justice is part of the socially embedded framework in which participants defined as part of their resiliency.

\subsection{Improved Outcomes and Circumstance}

Participants understood resiliency as enacting improved outcomes and circumstances among Bahá'ís in Iran facing systemic violence. Resiliency was defined as propelling them and their community forward, leading to improved outcomes and circumstances. It is important to note that this conclusion is only reflective of the responses from the 15 participants whom I interviewed, who are part of a group of BIHE alumni that do not live in Iran. This result in particular lays significance to those individuals who live outside of Iran in North America versus 
within Iran, and are subject to a vastly different environment with very different restrictions. Improved outcomes and circumstances could be in reference to BIHE allowing for participants to seek opportunities outside of Iran, utilizing their educational qualifications and experiences at BIHE. Their education at BIHE could be regarded as a route out of Iran, therefore not being subject to persecution, and therefore an improved outcome.

Although this study did not interview BIHE alumni living in Iran, a third of participants discussed how the existence of BIHE has contributed to the destigmitization of Bahá'ís in Iran among Iranian citizens and improvement of circumstances for Bahá'ís living in Iran. The social stigmatization that Bahá'ís have experienced in Iran is one aspect of the persecution and oppression they have faced. This reflection from participants contributes to the theme of improved outcomes and circumstance of BIHE alumnus. For example, if fellow Iranian citizens do not hold stigma for Bahá'ís, they may be more likely to hire Bahá'ís with BIHE degrees, advocate for Bahá'ís within their community, and socially accept Baha'is as part of their community. This invisible yet complex process may result in prevention of intensified persecution of Bahá'ís. The existence of a university allowing for a decrease in negative social stigma could possibly impact other areas of oppression such as in political and legal realms. Karlberg (2017) describes the Bahá'í view of the importance of "transformation of hearts among both the oppressors and the oppressed" (p. 232). In this case, a minority population seeks this transformation through means which develop tools that can advance discourse in Iranian society. The existence of BIHE may have contributed to the gradual impact of changes in attitudes and stigma for the Bahá'í community as whole in Iran. One participant stated how she understood the impact of BIHE on Iranian society (2020): 
When I told my friends, my non-Bahá'í friends about my university and the difficulties that we had, they were very shocked and couldn't believe what is going on for Bahá'ís and how difficult our situation is. They had more empathy for us. It has had a positive effect because they see how much we have difficulties for the simple rights that every citizen should have, to study, and go to university. They realized that we are treated like a second-degree citizen. We don't have access. We are Iranian. We are part of, we are Iranian citizens, and we can't go to university. It was shocking for them that we can't access simple facilities that is the right of everybody. BIHE had a positive impact because people are thinking about the Bahá'í community, about BIHE, and the value of education in the Baha'i community.

These words express the discriminatory policies that Baha'is face in Iran, and how the response of the Bahá'í community is gradually impacting the sentiments of how mainstream Iranian society views Bahá'ís. It also demonstrates the significance of BIHE as an institution influencing the wider community it exists within, as well as how this influence improves the circumstances and lives of Bahá'ís in Iran.

In terms of reflecting on improved outcomes and circumstances for participants themselves, they identified the development of individual qualities and capacities as part of their resiliency. Based on the information previously discussed in Chapter 4.4, the advancement of the individual's qualities allowed for their circumstances and individual outcomes to improve and propel forward.

The existence and successful operation of BIHE as an educational institution has also allowed for improved circumstances among generations of Bahá'ís. As discussed in previous sections, BIHE as an institution has allowed for students to attain degrees at BIHE and also 
obtain degrees that are recognized outside of Iran to attain further education. As a model of institutional resiliency and achieving improved outcomes, participants have also achieved and attained improved outcomes and circumstance as part of their resiliency.

The attainment of knowledge and the achievement of degrees was previously discussed in this chapter in examining the development of the individual in relation to resiliency as well as how this attainment was an act of resistance itself. However, it should be emphasized that the result of this contributes to the theme of improved outcomes and circumstance, which was a prominent part of how participants defined resiliency. As highlighted earlier, by not accepting an entire generation of a minority group to be uneducated, BIHE students are impacting future generational oppression and are improving intergenerational outcomes and circumstances.

Furthermore, participants understood their experience and resiliency as having a protective nature in bettering their outcomes and circumstances. This was within Iran but also how international bodies intervene preventing further persecution, and thereby improving circumstances for Bahá'í students. Many BIHE alumni prioritized participating in international advocacy in their communities for BIHE following their transition from leaving Iran and highlighted the importance of putting such pressures on government bodies. One participant shared the anecdote that "the advocacy of the Bahá'í world at the United Nations for the rights of Bahá'ís has had a huge impact on the everyday life of BIHE students" (2020). Such advocacy has likely resulted in the prevention of further persecution and attacks on BIHE, through means of international pressure and awareness of human rights violations.

By having the tools, personal qualities, and community structures for advocacy, participants understood that they are able to improve circumstances for Bahá'ís in Iran. The practical skills and qualities that BIHE alumni gained have allowed them to communicate and 
advocate for the operation of an educational institution in a country where Bahá'ís are unable to access higher education. This has resulted in improved circumstances and outcomes, allowing for a university to operate and students to continue attaining knowledge and obtaining degrees.

Students drew on the socially embedded nature of their community and their own skills which allowed for them to propel and improve their outcomes and circumstances as Bahá'ís in Iran seeking an education. According to participants, the establishment and operation of BIHE as a response to violence has improved the lives of Bahá'ís from Iran as an oppressed minority religious community. Many of the areas in which outcomes and circumstances are closely intertwined to one another and have allowed for profound positive impact. Improved circumstances and outcomes were seen in individual development, a thriving educational institution, educational achievement, destigmatizing of Bahá'ís in Iran, and advocacy efforts.

\subsection{Lack of Barriers and Forward-Propelling Outcomes}

Participants understood resiliency as being a force which propels and advances entities forward to achieve goals that may have otherwise been unrealistic or unfeasible. This force is intertwined with the community modelling this process and is mimicked and reflected onto the individual's journey. This mode of resiliency is not passive to systematic barriers in regards to achievement or trajectory, regardless of intentional obstacles. Participants understood resiliency as propelling them forward to fulfill aspirations that seemed to be unrealistic given the situation of Bahá'ís in Iran. This included advancement in their own lives, and advancement of a community wide endeavour as a socially embedded process. In examining theory, data, and the voice of participants, I will discuss how participants understood resiliency to lack barriers and be grounded in outcomes which propelled them forward. 
It is important to note that BIHE alumni interviewed for this case study were all former students that no longer live in Iran and were able to utilize their degrees because of their current country of residence. Perhaps a lack of barriers and advanced outcomes which participants shared as part of resiliency is unique to BIHE alumnus living outside of Iran. This emerging theme could appear differently among BIHE alumnus living in Iran. Although there may be differences in how outcomes are propelled among groups within Iran and outside of Iran, the very existence of an operating university may speak to a lack of barriers in which resiliency was described as by participants.

One participant described their resiliency as being able to propel forward without systematic restrictions by discussing their journey of their advancement in academia, where they are now a full professor in North America. Their roots in academia commenced in a country where they were arrested, interrogated, and imprisoned for taking exams for their unrecognized bachelor's degree at an underground university. For this participant, their resiliency was the process of propelling forward and achieving goals beyond the expectations that their country had for them, and despite critical barriers.

This understanding differs from other standard definitions of resiliency. Participants did not resonate with resiliency theory in accurately defining their experience and understanding of resiliency. Luthar (2006) describes resiliency as a form of "positive adaptation" (p. 6) in the face of adversity. Similar definitions by Ledesma (2014) conclude the resiliency as the process to "bounce back" (p. 6) when facing trauma. As discussed earlier in the theoretical chapter, these definitions are vague whereby the degree of adaptation is unknown. In understanding the phrases to of "bounce back" (Ledesma, 2014, p. 6), resiliency under this theoretical umbrella would 
mean to return to a previous baseline state. Participants in this case study did not understand resiliency in this way and did not express or mention these concepts in discussing resiliency.

I find the terms of "bounce back" (Ledesma, 2014, p. 6) to be inappropriate in a context of generational persecution and trauma. This concept raises questions of applicability given minority groups such as Bahá'ís that have faced oppression for generations. What would group's such as these be "bouncing back" to? The propelled and unrestrictive nature of resiliency among participants was emphasized throughout interviews. At no time throughout any of the 15 interviews that took place did any participant indicate that BIHE would help them reverse to a old normality. Resiliency was understood as a set of qualities and achievements among the individual, supports and resources among a community, and a force that advocates for long term change which will be further discussed. Resiliency for participants was characterized by propelling forward and advancing on trajectories that were not subjected to defined limits.

Furthermore, the compensatory model shared similar limitations with resiliency theory, in how both theoretical approaches create limits and barriers of resiliency. The compensatory model approached resiliency as the ability to "neutralize risk" (Ledesma, 2014, p. 2) which is contradicts the concept of propelling forward. Participants in this study would argue that "neutralizing risk" is not a part of their definition of resiliency, and shares similar limitations as resiliency theory. Instead, 75 percent of participants understood resiliency as a form of resistance through the capacity of building and contributing. This definition goes beyond the compensatory model's neutralization of risk, which may be restricted to only neutralizing a violent situation. The perspective which participants shared was one that understood resiliency to go beyond neutralizing adversity but alternatively forging ahead and advancing by propelling to a new reality, that was not previously part of their path. 
Participants expressed the nature of resiliency to not be subject to restrictions and barriers when asked to share insights with other oppressed minority groups. Ninety-three percent of respondents shared encouraging words that perseverance through hardship would allow them to achieve whatever they want to, even if it appears to be impossible. This too was not a message with barriers and limitations or focused on solely dissolving risks. Instead, participants embraced what could be considered at some points in their life as impossible. One participant shared the following anecdote, demonstrating the lack of barrier that participants believed for themselves and their resilience (2020):

We need to realize that there is a lot of injustices in the world, and we all need to work toward eliminating those injustices, but that's our reality. Our starting points are not the same. Someone starts at +500 , someone starts out at -300 . That is the world. It's not fair, but we need to have faith that if we instead of putting our energy towards criticizing why we are at -300 , if we put our energy toward how we can strive and how we can come together as a community and work together to respond to that injustice that is facing us, we can strive on.

In this participant's response, the individual who starts life at -300 does not accept the -300 as their norm to "bounce back" to. A baseline of -300 , perhaps could be being born into a family that faced limitations because they are an oppressed minority. As this child becomes a young adult, they face new challenges and experiences of turmoil, such as arrests and prison because they want to access education and attend university. Being arrested or imprisoned could decrease their quality of life to a -500 . "Bouncing back" from -500 to the original -300 was not an option for participants and therefore impertinent to the findings of this case study. I would argue that participants approached this analogy that regardless of starting at -300 or -500 or -1000 , 
oppressed minorities can achieve any positive numerical value in this analogy that they wish to achieve. Another participant that had faced multiple arrests and interrogations in Iran because they were a student at BIHE, shared their experience of the propelling forward as part of their resiliency (2020):

When I said nothing is impossible, I really mean that. You have to work for it, and you have to have a drive and passion, but I made it out of Iran, and I came here alone, and I got access to all this education. I think that anything is possible. You should just work towards it.

This participant had attained multiple graduate degrees following their education at BIHE. They understood that all possibilities are attainable, which goes beyond the compensatory model view of neutralizing a trauma to a previous state. Instead, they emphasized how the combination of a vision, purpose, and strong work ethic; all aspects of how they understood resiliency, to be crucial in overcoming barriers. Further, their view also highlights that possibilities are unrestrictive regardless of circumstance.

Being that this case study focuses on resiliency, I was surprised at the inapplicability and incoherence of mainstream resiliency frameworks versus how resiliency was understood in this study. Perhaps these other theories of resiliency are more applicable and relevant in a medical or clinical setting that focuses on the psychological nature of trauma. In such settings, defining healthy barriers and limits may be particularly useful. However, the element of limitations and boundaries within resiliency was not applicable for my participants. Note that when referring to mainstream resiliency theories, I am referring to a diverse body of scholarly work. The overwhelming bulk of this extant theory seeks to measure resiliency, unlike my study which allows participants to self-report and self-define resiliency. 
This study argues that the resiliency model in which the BIHE community demonstrates is embedded within the individuals within BIHE. Transitioning from the individual's advancement and propelled nature of resiliency, the community's advancement is part of the socially embedded process of resiliency. In examining community endeavours, BIHE as an educational institution reflects this notion propelling forward through resiliency. In previous sections, I discussed how community resiliency was a core part of how participants understood resiliency. The relationship between how community resiliency interacts with propelling forward without being subject to obstacles further emphasizes this point. The very existence and functioning of an internationally recognized university specifically made for a religious minority community that is not able to access education could be argued as reflecting this propelled advancement. In addition, the collaboration of almost 1000 volunteers that operate BIHE in a country where volunteers and students are putting their safety at risk, may also reflect this aspect of not being victims to systematic barriers due to the resiliency of a community. BIHE continues to graduate a cohort of students annually regardless of arrests and jail for many students and volunteer staff and faculty. This too, reflects a resilient community that is not subject to a certain specific amount of achievement or accepts a low ceiling of expectation.

Unlike resiliency theory and the compensatory model, resiliency in this study was characterized by propelling forward, and was not subject to systematic barriers or persecutory obstacles. Participants understood their resiliency without what one may shape as being realistic and pragmatic in a violent circumstance. Instead, resiliency could lead to any outcome, without the barriers associated with a victimhood identity. This view of resiliency is coherent with constructive resiliency, which also defines resiliency as having a perpetual advancing element, despite barriers. As individuals, BIHE alumni have forged forward to advance in their own lives 
without imposed limitations, and as a community, BIHE has survived and thrived despite oppression as an educational institution regardless of barriers.

\subsection{Non-violent Approach}

A non-violent approach is integrated into the definition participants described as core to the process and quality of resiliency. Participants from this community link non-violence to be at the nucleus of how they define resiliency. Within the context of a socially embedded process of resiliency, they saw how their institution responded non-violently to oppression and the individuals within mirrored that same approach in how they too enacted resiliency. The approach of BIHE as an institution, a Bahá'í university, is reflected theologically in how the Bahá'í religion views non-violence:

If others hurl their darts against you, offer them milk and honey in return; if they poison your lives, sweeten their souls; if they injure you, teach them how to be comforted; if they inflict a wound upon you, be a balm to their sores; if they sting you, hold to their lips a refreshing cup. ('Abdu'l-Bahá, p. 320)

This socially embedded interaction of resiliency within community values and beliefs resulted in non-violence being part of how they defined resiliency. They understood their education at BIHE as part of a greater act of resistance which was core to the process of their resiliency, previously discussed in Chapter 4.5. Characterizing BIHE as a tool of resistance, participants distinguished their particular approach to oppression as a form of non-violent resistance. They distinguished how their resiliency and outcomes were reflective of their non-violent approach. Participants understood the process of resisting oppression and particularly resisting oppression non-violently as part of the process of their resiliency. 
Recall above in section 3.5, I discussed non-violence theory. I will now discuss how nonviolence applies in conjunction with the results of this study in understanding resiliency among BIHE alumnus. The non-violent approach that alumni from BIHE took to resist oppression empowered BIHE students, and the Bahá'í community in Iran. The existence of this empowerment through non-violent means is described by participants as part of their resiliency. One participant shared the following anecdote on how they relate non-violence to resiliency in the context of Bahá'í students in Iran (2020):

All the doors are locked, and all the doors are closed for Bahá'ís to excel in education and many areas, but instead of having a violent head on fight with it, BIHE students are trying to build something in their own way. Obviously sitting there and doing nothing is not the way because no one will even know that there is any oppression, but I think doing something constructive, and finding a way of knowing what they want and going after in different ways and thinking in different ways than what is customary is resiliency. By fighting oppression without violence, they don't lose time and at least make something beneficial and positive out of the experience.

Participants understood resiliency as taking a non-violent approach as an individual interacting in a society, regardless of if it is violent in nature. Participants defined resiliency at its core to be part of a non-violent response. One participant referred to this non-violent approach sharing that "BIHE is a very good example of how you can fight persecution. It doesn't have to be violence, BIHE proves it. Fighting persecution doesn't have to be violent" (2020). They understood that combatting persecution does not require violence, and in turn, this forms resilience.

The institutional model of resiliency which BIHE portrays has been mirrored onto individuals as part of the socially embedded nature of resiliency. Participants saw themselves as 
resembling the approach to challenges on an individual level that BIHE takes on at an institutional level. This includes the approach of non-violence to oppressive situations. As previously stated, participants shared frustrations with having their school website and school materials continuously blocked by the government. In response to this barrier, BIHE students became habituated to troubleshooting and using their resourcefulness to gain access to their school materials non-violently. Gaining access to school websites was not characterized by violent protests demanding internet access. Rather, they developed the mentality that if server one is blocked, then try server two, and so on, until they were able to reach their goal. Participants found this process of resiliency and the resourcefulness they gained through nonviolent means to be transferrable to their lives outside of BIHE into future endeavors. There is a strong aspect of futurism in how resiliency from BIHE functions in the long term and continues to be beneficial to participants.

Further, two-thirds of participants defined resiliency as a form of non-violent resistance and the capacity to build and contribute. Sharp's theory of non-violence and specifically nonviolent intervention is based upon a disruption due to a non-violent development of a parallel system. One participant in this case study stated their understanding of the impact of a nonviolent parallel system (2020):

I think the power of resilience and peaceful action under oppression, is way stronger than conflict and protest, because I've seen it first-hand so not give up, find ways around it, to find peaceful ways around oppression.

This form of intervention is considered to be the most impactful method out of the classifications of nonviolent action (Sharp, 1987). Demonstrating Sharp's theory of non-violent intervention, another participant shared the following anecdote (2020): 
We could say that the government of Iran is corrupt so based on that we are suffering, so we could do something like kill people, but we did the opposite. We tried to make a university, even though it is very small.

Instead of combating violence with more violence, participants understood that they responded to violence through education. This creation of a parallel system as a nonviolent tool to oppression is impactful theoretically, but also practically in the setting of BIHE. Bahá'í students in Iran are channeling their acts of nonviolence towards developing a new system. In addition, when participants were asked what message or insights they would share with other oppressed minority groups, almost half of the participants shared their advice to approach their oppression non-violently. A participant described this notion of responding to violence, non-violently, in the following excerpt (2020):

People who resist or revolt, even if you did, it wouldn't do any good, so the best logical option was a to find a better way...I look back and think my mind was trained to look for another way, to look for another solution. Okay this didn't work, another one, that's fine, another one. I think that's the whole idea that's why those kinds of setbacks aren't seen as drastic as it might have been seen from outside, because you're used to it but by itself it is tragic. You're sitting somewhere just taking a test and some people comes with guns and cameras going around you as if you've committed a crime. It could be scary. It is scary.

As illustrated, the approach of non-violence is at the core of how participants in this study understood their response to conflict, violence, and a significant aspect of their resiliency. Furthermore, Sharp discusses the shift in power from the oppressor to the oppressed through non-violent acts (1959). Data from the current study shows that one third of participants found 
that their education at BIHE shifted control being taken away from them, to empowering participants with a tool of resistance. The empowerment was based on behaviour that was characterized by non-violence.

The theoretical approach of constructive resiliency in understanding resiliency, moves away from traditional responses to violence, and resonated with how participants understood resiliency in this case study. Abay and Vedovi (2017) describe constructive resilience as the "moving toward a sustainably violence-free society will ultimately entail creating patterns of social engagement that move away from contention and toward collaboration, even while practical measures are taken to address injustices and suffering." BIHE alumnus from this study understood the impact of non-violence on a violent society to be profound and productive. Constructive resiliency, which is characterized by non-violence, goes beyond the establishment of logistical resources but emphasises the deeper intention of "transformation of the hearts among both the oppressors and the oppressed" (Karlberg, 2010, p. 232). Participants understood the impact of their non-violent decisions and actions as slowly transforming the hearts within an oppressive environment.

In addition, one participant shared how in a systematically oppressive environment, particularly like in Iran, knowledge is a form of power. They discussed how the act of taking classes at BIHE students allowed for students to gain more knowledge, thus granting their minority group some power over themselves. Gaining power through taking classes is an act of non-violence. The acts of non-violence in this instance constructively shifted power to a targeted minority group. Power reflects having agency over oneself and this sense of agency is reflective of why participants included non-violence in their definitions of resiliency. 
BIHE as an institution utilized a non-violent approach to respond to violence. Participants viewed this aspect and approach as being ingrained within resiliency of their community. The socially embedded nature of resiliency among BIHE participants also reflects a non-violent approach to violence from the individuals that were part of BIHE. Although my study solely examined BIHE alumni, Sharp's theory of non-violence is utilized for diverse contexts. The significance of a non-violent approach that is intertwined with resiliency in this study may have implications for other communities that face intergenerational violence. A non-violent approach to oppression was a significant theme in defining resiliency among participants and intertwined in how participants understood improved outcomes, advanced qualities among the individual and community, and seeking means of justice. Furthermore, participants understood non-violence as being integral to a socially embedded process, whereby the community and individual work together in a way that is characterized by non-violence.

\subsection{Means of Seeking Justice}

Participants also included practical means of seeking justice within their definitions of resiliency. Concrete steps towards justice is deeply connected with the other themes that act as pillars for one another. A means of seeking justice was ingrained in how participants defined resiliency: 60 percent of participants defined resiliency as a form of attaining justice and resisting injustice. Shedding light from this empirical finding, in this very specific context, participants linked resiliency with forms of justice as it allowed them to feel empowered and survive while being persecuted. Participants understood attaining justice and not being a victim to injustice to be interwoven in resiliency. Correlating with earlier discussion points, seeking justice included the ability to access education, international advocacy efforts, resisting oppression, and relate to bettering circumstances for the individual and community. As these points are intertwined within 
this emerged theme, I will discuss means of seeking justice in how it theoretically relates to this case study in understanding resiliency. Generally speaking, there may be individuals who identify themselves as being resilient but do not place significance on seeking means of justice. This is a distinguishing factor of how this particular population from BIHE defines resiliency for themselves.

Resiliency is part of the nexus of adversity and is demonstrated or mentored if there is the existence of a challenge or a problem. Without an inverse and close relationship with adversity, resiliency itself would not exist. Participants understood that part of resiliency is taking steps to overcome the adversity through concrete and substantial means. They understood their attained quality of resiliency as part of a process of resiliency which responds to injustice through practical measures. The example most used was the creation and operation of BIHE as being part of their resiliency and intertwined with an effort to seek justice, so themselves and their community would not be subject to oppression from their oppressor. Resiliency as a quality reflects the characteristics and abilities of being able to seek various means of justice. Participants understood that resiliency as a process allows for a cycle of seeking justice and in turn, through practical means, opening doors for further resiliency. The quality and process of resiliency that participants defined can be demonstrated by the example of the creation of BIHE itself as a resilient act, and the process of attending BIHE being adverse in many respects whereby they may have been arrested or imprisoned, but because they were resilient, they could withstand external pressure and persecution and continue to be resilient, allowing for future generations to have access to justice in this regard; an education. For participants in this study, practically responding to adversity by seeking justice is ingrained in resiliency. In their unique context, resiliency is part of the process and qualities needed in responding to oppression. 
The constructive resiliency theory is strongly aligned with how participants understood this particular aspect within resiliency; seeking means of justice. Constructive resiliency moves towards approaches that earnestly build justice, while broadening options and structures available for persecuted communities to utilize. The conceptual framework of constructive resiliency approaches social transformation whereby it is characterized by a mode of purposefulness and proactivity in responding to oppression and persecution through steps which are non-violent and non-adversarial in nature (Javaheri, 2018). This attribute of responding to oppression and persecution through concrete steps is fundamental in seeking justice in an unjust situation. This too is directly relevant to the experience of seeking means of justice as part of resiliency.

Participants identified the act of accessing education in a society where they were deprived of education as a means of seeking justice. The act of becoming educated and skilled in their respective fields was a means of justice and resiliency for them. The act of creating an educational institution was a means of replacing injustice with justice for participants.

International advocacy efforts were also a means of seeking justice for participants and ingrained in their resiliency in an oppressive environment.

Seeking means of justice through identifying and engaging in concrete steps towards alleviating injustice, is at the nucleus of BIHE. For Bahá'ís in Iran, resiliency is not submissive, passive, or patient acceptance of injustice. It also does not rely on a mysterious divine power, disconnected from their actions that can "free them from the chains of oppression" (Javaheri, 2018). Community members both in Iran and outside of Iran pursue legal avenues to prevail justice and are "creating patterns of social engagement" that advance and progress rather than contribute to contention (Javaheri, 2018). Participants understood resiliency as being interwoven 
into a process of abolishing injustice while simultaneously establishing and building justice into their environment. Notwithstanding violent circumstances, prioritizing justice while responding to routine persecution granted BIHE students the sentiment of resiliency defined by participants. Through progressive steps towards eliminating injustice, oppressed minority communities can have opportunity to prosper and be resilient.

\subsection{Summary}

Based on responses from participants at BIHE, this case study contributes to the theory and literature of resiliency in proposing that resiliency is a socially embedded process. In the case of participants from BIHE, this socially embedded process also propels the individual and the community forward, improving their circumstance through non-violent means of resistance and seeking justice. In building out this definition, I discussed the following prominent themes that arose from my research on resiliency among BIHE alumnus: a socially embedded process, advancing resources within the community, building capacity and qualities within the individual, tools of resistance, improving outcomes and circumstance, a lack of systematic barriers and propelled outcomes, a non-violent approach, and lastly, the means of seeking of justice. The socially embedded nature of resiliency is intertwined with the community and the individual, which cultivates the various components of resiliency. The community acts as an institutional model of resiliency, allowing for the community to thrive and individuals to mirror the approach in which the community undertakes. In addition to discussing data results, and vignettes from participants, I utilized interdisciplinary theoretical framework where I explored resiliency theory, the compensatory model, non-violence theory, community resiliency, constructive resistance, and constructive resilience. 
I found that constructive resiliency defined how participants understood their own resiliency and the resiliency at BIHE. Although experiences of participants relate to other theoretical frameworks, constructive resiliency was all encompassing in how it was inclusive of non-violence, resistance, and community collaboration. An element which was not included in previous theories that is unique to constructive resiliency and applicable to this case study was the significance of transforming attitudes of dominant oppressive structures. BIHE has not only had an impact on individual outcomes, but also on a perceived gradual transformation of community through steps of reducing stigma of a religious minority group. Participants perceived BIHE as transforming the violent context in which they lived in. The approach of constructive resiliency which this study takes on was eloquently describes by one participant, that I believe also encompasses what resiliency means among Bahá'í minorities in Iran (2020): Resiliency for me is the capacity to fight back, to resist, to stand in the face of injustice or in the face of hardships leading unto qualities of characters or spiritual qualities that everyone has, or a community has. The capacity to be build, resist, define and redefine yourself and your experience in the face of injustice.

Resiliency is intricately tied to responding to adversity for participants and can have long term consequences for participants and oppressed populations. Participants in this study all benefited throughout their lives from the qualities they gained and education they obtained through their involvement at BIHE. Regardless of many participants being imprisoned in Iran due to their involvement at BIHE, they viewed BIHE as a positive force contributing to their resiliency. BIHE was a socially embedded process of the individual and the community which modelled resiliency as an institution onto the individual. Participants did not view their resiliency as 
bouncing back to a previous norm, rather as bounding forward, propelling and forging ahead, regardless of systematic barriers.

BIHE alumnus challenged theoretical frameworks of resiliency. This case study proposes a socially embedded nature of resiliency that interacts closely with the community and the individual that fosters and fuels the different aspects of resiliency which participants describe. Further, constructive resiliency aligns with how participants of a minority group that have been systematically and generationally persecuted and oppressed define resiliency. The experience of Bahá'í students in Iran, responding to violence through education, surpasses the limiting factors of standard definitions and theories of resiliency. Rather, participants emphasized the propelling and boundless nature of resiliency in response to turbulence.

Both resiliency theory and the compensatory model on resiliency contradict how participants from BIHE defined and understood resiliency. Both approaches to resiliency impose limits and barriers on the capacity of an individual or community. The use of language such as "bouncing back" or the process of "neutralizing risk" in describing resiliency did not capture the experience of resiliency among BIHE alumnus. Standard definitions of resiliency like resiliency theory and the compensatory model on resiliency do not account for the 'after' of a challenging event or address chronic intergenerational persecution. Nor do they adequately account for the importance of the community and individual fostering resiliency. This indicates a need for a more thorough and absolute definition of resiliency to accurately describe the process and qualities BIHE alumni resonated with.

Community resiliency was also examined in relation to the experience of BIHE as a community-oriented educational institution. Participants heavily attributed and ascribed the 
success of BIHE and its constituents to the collaborative and resilient community of BIHE. While participants resonated with the community resiliency approach, they also emphasized the role of the individual. Although resiliency of the community was of great value among participants, they understood the community as part of a socially embedded process that continuously interacts with individuals therein. Furthermore, community resiliency did not explicitly identify other aspects of how participants understood resiliency and its outcomes. This includes pragmatic means of seeking justice, forms of resistance, developing qualities within the individual, with a posture of acting non-violently regardless of circumstance.

Further, non-violence theory and constructive resistance, although pertinent to the experience of BIHE alumnus and how they understood resiliency, are not resiliency theories themselves. Non-violence theory and constructive resistance were intentionally included in this case study, as they were interwoven into how participants defined resiliency. The usage and integration of non-violence and resistance have been traditionally examined in literature on combating oppression. However, this integration is novel in conceptually understanding the interdisciplinary framework of resiliency and is unique to the constructive resiliency model of resiliency.

Constructive resiliency explicitly defines how BIHE participants, as an oppressed minority group, understood resiliency. The propelling attributes and lack of restrictive boundaries of this type of resiliency was at the core of how participants understood resiliency. Its very nature is embedded in a social process where the individual and the community mutually depend on one another, and both build together simultaneously. Community institutions, structures, resources, and collaborative skills advance and lead to systemic opportunities for the 
individual and for the community. Concurrently, the individual can develop qualities, access knowledge, and obtain formal education and degrees, leading to individual growth. The socially embedded disposition of resiliency allows for tools and strategies of resistance. BIHE alumnus understood the existence of BIHE as an act of resistance itself. Within BIHE, they understood their daily choices of studying, completing assignments, and participating in exams all to be profound acts of resistance. Participants also explicitly incorporated a non-violent approach in understanding their resiliency and how resiliency is achieved. The intersection of these features of resiliency participants described, led to concrete steps of seeking justice and improved outcomes and circumstances, which encompasses how participants understood resiliency. 


\section{Chapter 5: Conclusion}

Employing a diverse theoretical framework, and engaging in data analysis, this case study proposes the following prominent themes in accurately defining resiliency among BIHE graduates: a socially embedded process, advancing resources within the community, building capacity and qualities within the individual, tools of resistance, improving outcomes and circumstances, the lack of barriers and propelled outcomes, a non-violent approach, and lastly, a means of seeking of justice. Elaborating on definitions of resiliency, this case study contributes to the theoretical framework of resiliency by highlighting a socially embedded nature that intertwines the community and the individual. The social embeddedness of resiliency fosters a sense of overcoming adversity. This fostering interacts with resistance and non-violence, and propels constituents, which all fuels resiliency.

This research highlights generations of BIHE alumnus who have contributed to overcoming oppression through the experience and process of studying at BIHE. Resiliency has been a key aspect of their lives and helped them see life from a vantage point that rejects victimhood and embraces overcoming. As shown, Bahá'ís in Iran have been intergenerationally oppressed and persecuted as a consequence of their religious beliefs and affiliation. They have encountered chronic and intergenerational adversity through continuous acts and forms of violence. The resiliency to violence that this case study examines is the systemic barrier of accessing university education imposed on Bahá'ís in Iran. The unique response of Bahá'ís in Iran accessing education, despite significant obstacles, led to questions of what exactly allows for the operation and existence of an underground university within a state of violence to be accomplished. 
One theoretical reflection on this work is how resiliency is embedded in the operation of BIHE. Participants highlighted how resiliency was modelled to them during their studies at BIHE because it is built into how the university functions and operates. Beyond educational content, students are taught that when one path is shut down, one should calmly resort to exploring alternatives. BIHE as an institution is a model of resiliency that is being taught through example to students. The concept can be illustrated by a participant's narrative, shared on page 74, discussing how BIHE as an institution responded to significant barriers. This student's thesis supervisor was arrested and imprisoned for teaching at BIHE, and the institution found this student another thesis supervisor. This process of arrests and transitions unfortunately repeated until a fourth thesis supervisor was able to support this student until their graduation. The process of resiliency demonstrated in this narrative is modelled within the context of the operation of BIHE. I argue that this model of resiliency allows for students to model the behaviours of BIHE within their individual contexts.

This raises interesting implications for institutions that work in adversarial contexts. If institutions model resiliency themselves in their functioning, are they better sites for teaching resiliency to their constituents? The definitions of resiliency found in literature do not include this aspect of how resiliency is fostered and nourished. My critique is that many of the definitions of resiliency discussed do not view resiliency holistically or use an intersectional lens on adversity and the process of building resiliency. Instead, minority groups like the Bahá'ís in Iran are engaging with intergenerational oppression and current oppression. Their parents, grandparents, great-grandparents, experienced intergenerational oppression, and they themselves currently face oppression. This vastly differs from typical clinical contexts of responding to adversity with resiliency. 
I find constructive resiliency best suits an intersectionality lens on adversity and the process of building and modelling resiliency in the context of BIHE students. I propose that we must view, examine, and understand the nature and actors in specific aspects to understand the concept of resiliency while acknowledging the important role of a socially embedded process.

The violent exclusion of higher education that Bahá'ís face is fundamentally predatory and has consequences on the socioeconomic status of the entire minority group. Unfortunately, many other minority groups globally face intergenerational predatory violence through oppressive and persecutory policies. The unique model that Bahá'ís in Iran have demonstrated may be beneficial to other oppressed minority groups in overcoming adversity and violence. Moving away from a victimhood identity that surrenders to the oppressor, and moving away from acts of violence and contention, Bahá'ís in Iran at BIHE have exhibited a solution of constructive resiliency. The institutional model of resiliency described in this case study acted as a model for BIHE students but can also act as a model for other oppressive contexts. The unique element of empowerment acted as a central thread throughout this research and could be applied to a variety of disheartened populations.

Contextualizing this case study onto social change may lead to peacebuilding strategies allowing for the oppressed to thrive. The contribution of resiliency being socially embedded could be applied to minority groups that are actively responding to oppression. This could occur within communities whereby minorities are implicitly or explicitly oppressed as well as minority groups that face significant systemic forms of abuse, violence, and exclusion. Future research could apply constructive resiliency as a model to other minority communities that face systemic violence. In investigating this model, future research could also utilize a comparative analysis of 
BIHE graduates along with learning about strategies and responses from other minority groups that have also faced systematic persecution. This could be with minority groups such as the Uyghurs in China, Indigenous communities in Canada, Black Americans in the United States, and other justice seeking groups in oppressive contexts.

The theoretical contribution of a socially embedded process is in response to defining resiliency in the context of intergenerational oppression. In conditions of intergenerational oppression, traditional resiliency theories such as resiliency theory and the compensatory model of resiliency are not applicable and relevant as they are not intergenerationally informed. They refer to events within a condensed time frame that occurred and offer explanations of returning to the previous normal before adversity was inflicted. This approach cannot be applied to an intergenerational context because for participants, there is no previous normal in their life span which they seek to return to as resilient individuals and as a resilient community. My theoretical contribution is that in contexts of long-term oppression, we must consider how community is involved and how resiliency as a quality and process can be learned and taught. BIHE exemplifies that an institution can teach resiliency. Therefore, this is something that can be learned but communities need to be socially embedded.

In the case of BIHE, interviewees described this process as a positive and forwardlooking movement that propelled them in many different areas of life. Participants understood that the socially embedded nature of resiliency moved them as individuals and their community forward. It cannot be assumed that the resiliency discussed in this work is guaranteed to propel other minority communities forward. If I were to create a theory of resiliency just for the context of BIHE alumnus that immigrated to North America, I would also add that this positive view of increased personal security, personal materiality, and improved stability because all participants 
shared these views. Participants understood that their resiliency was partly due to an improvement of material conditions. However, I cannot generalize this piece to other populations as they may have different material conditions and I do not have enough data points.

The significance of this case study has implications on advancing discourses on resiliency, oppression, and resistance. In specifically examining the population of Bahá'ís in Iran, findings from this study contribute to the notion that Bahá'í alumnus are enacting constructive resiliency in response to violence. BIHE alumni that participated in this study understood regardless of the obstacles and barriers they have been subject to, that they have been able to propel and advance as individuals and as a community.

Future research endeavours could also further examine resiliency among BIHE alumni with a significantly larger sample size, leading to increased reliability. This thesis should therefore be seen as a pilot study. A much larger study would be needed to test out what shapes the dynamics of resiliency in how it is formed. I was limited in how many participants I interviewed as well as the diversity of participants that live in North America versus BIHE alumni living in Iran. Although this limitation is due to safety considerations, the individuals I interviewed are not fully representative of the BIHE population as a whole and therefore not comprehensive. My results are skewed to one type of graduate that was able to cross borders and reside in North America. A study with a broadened participant demographic could provide a more extensive and in-depth analysis on resiliency among a minority population that has faced intergenerational and continues to experience oppression.

The particular use of language and definitions to describe resiliency likely shape how groups that are persecuted see themselves and respond to violence. Constructive resiliency 
among participants encompassed their experience of sentimental and tangible empowerment. In the case of Bahá'ís in Iran from this case study, this specific type of resiliency was a quality they all possessed that acted as an armour to withstand violence and achieve justice for themselves and their community. Participants strived to methodically fulfill all aspects of constructive resiliency including a non-violent approach to violence, contributing to community endeavours, advancing their educational attainment, and developing skills, gaining tools of resistance, and improving outcomes and seeking justice. Through the constructive resiliency of Bahá'i students in Iran, BIHE as an entirely functional educational institution, and the Bahá'í faith as a religious group, community members have been able to survive crisis and thrive despite oppression. The socially embedded framework of resiliency which this study proposes emphasizes the interwoven role of the community and the individual, a mutually reinforcing interaction that enables both to propel forward. 


\section{References}

Abay, N. and Velovi, A. (2017, June 15). Constructive Resilience and Women's Peacebuilding Movements. Berkley Center for Religion, Peace \& World Affairs at Georgetown University. https://berkleycenter.georgetown.edu/posts/constructive-resilience-andwomen-s-peacebuilding-movements

Abdu'l-Bahá, A. (1978). Selections from the Writings of Abdu'l-Bahá. Baha'i World Centre Publishing Press.

‘Abdu'l-Bahá, Gail, M., \& Khan, A. K. (1990). The Secret of Divine Civilization. Baha'i Pub. Trust.

Afshari, R. (2012). The discourse and practice of human rights violations of Iranian Bahai's in the Islamic Republic of Iran. In The Baha'is of Iran (pp. 246-291). Routledge.

Affolter, F. W. (2005). The specter of ideological genocide: The Baha'is of Iran. War Crimes Genocide \& Crimes Against Human., 1, 75.

Affolter 1, F. W. (2007). Resisting educational exclusion: The Baha'i Institute of Higher Education in Iran. Diaspora, Indigenous, and Minority Education, 1(1), 65-77.

Ahmed, S. M., \& Palermo, A. G. S. (2010). Community engagement in research: frameworks for education and peer review. American Journal of Public Health, 100(8), 1380-1387.

Akbar, A. (2021). Freedom of Religion: The Contribution of Contemporary Iranian Reformist Scholars. Religions, 12(6), 384.

Assadi, T.O., \& Lloyd, B. Role of Information Technology in denial of education: An underground university perspective. (Assadi \& Lloyd, n.d.) 
Bahá'í International Community. (2016). The Bahá'i Question Revisited: Persecution and Resilience in Iran. www.bic.org/sites/default/files/pdf/thebahaiquestionrevisited final160930e.pdf

Bahá'í International Community. (2017). The Bahá 'is. Office of Public Information of the Bahá'i International Community.

Bahá'í International Community Representative Offices. (2021). About us. https://www.bic.org/about/about-us

Bahá'í Reference Library. (2008a). A Compilation on Bahá'í Education. https://reference.bahai.org/en/t/c/BE/be-10.html

Bahá'í Reference Library. (2008b). A Compilation on Bahá'í Education. https://reference.bahai.org/en/t/c/BE/be-17.html

Bahá'í Reference Library. (2008c). A Compilation on Bahá’í Education. https://reference.bahai.org/en/t/c/BE/be-63.html

BIHE. (2021a). Quick Facts. http://www.bihe.org/index.php?option=com content\&task=view\& $\underline{\mathrm{id}=146 \& \text { Itemid }=236}$

BIHE. (2021b). Faculty. http://www.bihe.org/index.php?option=com content\&task=view\&id=8 $\underline{0 \& \text { Itemid }=202)}$

Brookshaw, D. P., \& Fazel, S. B. (Eds.). (2012). The Bahá 'is of Iran: Socio-historical studies. Routledge.

Bonanno, G. A., \& Diminich, E. D. (2013). Annual Research Review: Positive adjustment to adversity-trajectories of minimal-impact resilience and emergent resilience. Journal of child psychology and psychiatry, 54(4), 378-401. 
Bottrell, D. (2009). Understanding 'marginal' perspectives: Towards a social theory of resilience. Qualitative Social Work, 8(3), 321-339.

Bourke, B. (2014). Positionality: Reflecting on the research process. Qualitative Report, 19(33).

Bozorgmehr, M., \& Douglas, D. (2011). Success (ion): Second-generation Iranian Americans. Iranian Studies, 44(1), 3-24.

Buck, C. (2020). Baha'i Faith: The Basics. Routledge.

Cameron, G., \& Momen, W. (1996). A basic Bahá 'í chronology. George Ronald.

Cameron, G., \& Ghanea, N. (2018). Baha'is in the Middle East. In Routledge Handbook of Minorities in the Middle East (pp. 170-184). Routledge.

Cheng, H. L., \& Mallinckrodt, B. (2015). Racial/ethnic discrimination, posttraumatic stress symptoms, and alcohol problems in a longitudinal study of Hispanic/Latino college students. Journal of counseling psychology, 62(1), 38.

Clarken, R. H. (2009). Iran's denial of education to Bahá'is. Detroit, Michigan: The Michigan Academy of Sciences, Arts and Letters. Wayne State University.

Cole, J. R. (2005). The Bahá'i minority and nationalism in contemporary Iran. Nationalism and Minority Identities in Islamic Societies, 127-163.

Cooper, R. (1985). The Baha'is of Iran: The minority rights groups, Report No. 51. Minority Rights Group.

Effendi, S. (1976). Epistle to the son of the wolf.

Fletcher, T. (2010). "Being inside and outside the field". An exploration of identity, positionality and reflexivity in inter-racial research. Leisure Identities and Authenticity. LSA Publication, (107).

Frankl, V. E. (1985). Man's search for meaning. Simon \& Schuster. 
Pohl, G. (1988). Report on the Situation of Human Rights in Islamic Republic of Iran. E/CN, 4, 24.

Ghadirian, N. (2008). An exploratory study examining the factors associated with the survival of underground education in an oppressive environment (Doctoral dissertation). Concordia University.

Greene, M. J. (2014). On the inside looking in: Methodological insights and challenges in conducting qualitative insider research. The qualitative report, 19(29), 1-13.

Guttman, A. (1994). Multiculturalism: Examining the politics of recognition. Princeton UP, Princeton.

Haghani, M. (2014). Iran Denies Education Rights to Baha’is. WJ Legal Stud., 4(1).

Hassan, H. D. (2007, May). Iran: Ethnic and religious minorities. LIBRARY OF CONGRESS WASHINGTON DC CONGRESSIONAL RESEARCH SERVICE.

Holmes, S. C., Facemire, V. C., \& DaFonseca, A. M. (2016). Expanding criterion a for posttraumatic stress disorder: Considering the deleterious impact of oppression. Traumatology, 22(4), 314.

IHRDC, i.e. Iran Human Rights Documentation Center (2006, December). A faith denied: The persecution of the Bahá'is of Iran. New Haven: IHRDC. Available at http://www.iranhrdc.org/114nglish/publications/reports/3149-a-faith-denied-thepersecution-ofthe-baha-is-of-iran.html [accessed 22 July 2016]

Javaheri, F. (2018). Constructive Resilience 1. The Journal of Baha'i Studies, 28(4), 7-89.

Karlberg, M. (2010). Constructive resilience: The Baha'i response to oppression. Peace \& Change, 35(2), 222-257. 
Kazemzadeh, M. R. (2019). Exploring Constructive resilience: A Qualitative Investigation of the Bahái Response to Oppression (Doctoral dissertation). University of Massachusetts Boston.

Kezar, A. (2002). Reconstructing static images of leadership: An application of positionality theory. Journal of Leadership Studies, 8(3), 94-109.

Khalighy, A. (2021). Liquid Pedagogy (Doctoral dissertation).

Koefoed, M. (2017). Constructive Resistance in Northern Kurdistan: Exploring the Peace, Development and Resistance Nexus. Journal of Peacebuilding \& Development, 12(3), $39-53$.

Kurtz, L. R., \& Turpin, J. (Eds.). (1999). Encyclopedia of violence, peace, and conflict, Vol. 1. Academic Press.

Lamont, M., Silva, G. M., Welburn, J., Guetzkow, J., Mizrachi, N., Herzog, H., \& Reis, E. (2016). Getting respect: Responding to stigma and discrimination in the United States, Brazil, and Israel. Princeton University Press.

Landinfo Country of Origin Information Centre (2017). Report Iran: The Situation of the Bahá'i community. Norweigan Country of Origin Information Centre. https://www.refworld.org/pdfid/5975fdb74.pdf

Lederer, Edith M. (2020). UN Investigator: Rights of minorities to worship undermined. AP News. https://apnews.com/article/religion-maldives-freedom-of-religion-discriminationnorth-korea-16c8581a5a00b5d4f0887e803e8c40dc

Ledesma, J. (2014). Conceptual frameworks and research models on resilience in leadership. Sage Open, 4(3), 2158244014545464.

Luthar, S. S. (2006). Resilience in development: A synthesis of research across five decades. 
Manocha, K., \& Tahzib, S. (2018). 15 Religion, social change and responding to persecution-the case of the Bahá'í community in Iran. Minority Religions in Europe and the Middle East: Mapping and Monitoring, 184.

Merriam, S. B., Johnson-Bailey, J., Lee, M. Y., Kee, Y., Ntseane, G., \& Muhamad, M. (2001). Power and positionality: Negotiating insider/outsider status within and across cultures. International Journal of Lifelong Education, 20(5), 405-416.

Mayton, D. (2009). Nonviolence and Peace Psychology: Intrapersonal, Interpersonal, Societal, and World Peace. Springer-Verlag New York.

Modood, T. (1998). Anti-essentialism, multiculturalism and the 'recognition' of religious groups. Journal of Political Philosophy, 6(4), 378-399.

Momen, M. (2005). The Babi and Baha'i community of Iran: A case of "suspended genocide?" Journal of Genocide Research, 7(2), 221-241

Momen, M. (2019). The Baha'i community of Iran: Cultural genocide and resilience. In Cultural Genocide (pp. 246-266). Routledge.

Nash, G. (1982). Irans secret Pogrom: the conspiracy to wipe out the Baha 'is. Spearman.

Novelli, M., \& Selenica, E. (2014). Protecting higher education from attack. Education Under Attack 2014, 99-108.

Patel, R. B., \& Gleason, K. M. (2018). The association between social cohesion and community resilience in two urban slums of Port au Prince, Haiti. International Journal of Disaster Risk Reduction, 27, 161-167.

Patel, S. S., Rogers, M. B., Amlôt, R., \& Rubin, G. J. (2017). What do we mean by 'community resilience'? A systematic literature review of how it is defined in the literature. PloS Currents, 9. 
Patfoort, P. (1987). An introduction to nonviolence: A conceptual framework. Fellowship of Reconciliation.

Patten, A. (2014). Equal recognition. Princeton University Press.

PBS News Hour. (2010, February 11). Timeline: A Modern History of Iran. https://www.pbs.org/newshour/politics/middle east-jan-june10-timeline

Pfefferbaum, R. L., Pfefferbaum, B., Van Horn, R. L., Klomp, R. W., Norris, F. H., \& Reissman, D. B. (2013). The communities advancing resilience toolkit (CART): An intervention to build community resilience to disasters. Journal of Public Health Management and Practice, 19(3), 250-258.

Pistor-Hatam, A. (2017). Non-understanding and minority formation in Iran. Journal of the British Institute of Persian Studies, 55, 1-12.

Rust, N. A., Abrams, A., Challender, D. W., Chapron, G., Ghoddousi, A., Glikman, J. A., ... \& Hill, C. M. (2017). Quantity does not always mean quality: The importance of qualitative social science in conservation research. Society \& Natural Resources, 30(10), 1304-1310.

Sanasarian, Eliz (2000). Religious minorities in Iran, Vol. 13. Cambridge University Press.

Sattarzadeh, S. D. (2015). Reading between the lines of rights: A critical analysis of international and national discourses (de) marginalizing indigenous and minority rights to higher education (Doctoral dissertation).

Sharp, G. (1959). The meanings of non-violence: a typology (revised. Journal of Conflict Resolution, 3(1), 41-64.

Smith, R. W. (1998). State power and genocidal intent: on the uses of genocide in the twentieth century (pp. 3-14). In: Chorgaijan, L. \& G. Shirinian (Eds.), State power. Studies in comparative genocide. St. Martin's Press. 
Sørensen, M. J. (2016). Constructive resistance: Conceptualising and mapping the terrain. Journal of Resistance Studies, 2(1), 49-78.

Taylor, C. (1997). The politics of recognition. New Contexts of Canadian Criticism, 98, 25-73.

Tavakoli-Targhi, M. (2008). 'Anti-Bahá'ism and Islamism in Iran'. In Brookshaw, D. and Fazel, S. (eds). The Bahá'is of Iran: Socio-Historical Studies. Routledge.

Tummala-Narra, P. (2007). Conceptualizing trauma and resilience across diverse contexts: A multicultural perspective. Journal of Aggression, Maltreatment \& Trauma, 14(1-2), 3353.

Ungar, M. (2004). A constructionist discourse on resilience: Multiple contexts, multiple realities among at-risk children and youth. Youth \& Society, 35(3), 341-365.

United Nations Human Rights Office of the High Commissioner. (2016, June 8). Iran: Most recent backlash against Baha'is expose authorities' extreme intolerance for religious group.https://www.ohchr.org/EN/NewsEvents/Pages/DisplayNews.aspx?NewsID=20073 $\underline{\& L a n g I D=E}$

Van Breda, A. D. (2018). A critical review of resilience theory and its relevance for social work. Social Work, 54(1), 1-18.

Warburg, M., (1999) Baha'i: A religious approach to globalization. Social Compass, (46)1, 4756.

Yazdani, M. (2015). Higher Education under the Islamic Republic: the Case of the Baha'is. Journal of Educational Controversy, 10(1), 7.

Zabihi-Moghaddam, S. (2016). State-sponsored persecution of Baha'is in the Islamic Republic of Iran. Contemporary Review of the Middle East, 3(2), 124-146. 


\section{Appendix A}

\section{Interview Questions}

1.) What years did you attend BIHE?

2.) What did you study at BIHE? Have you received further education?

3.) My interest in this project is about resiliency. Before we start talking about that, what does that mean to you, what do you hear?

4.) Using your definition of resiliency would you say that your education has helped you to be resilient?

4A.) If yes, in what ways, how do u see those, how do u define those?

4B.) If not, why not, and if not are there other qualities or other words that would better describe?

5.) Do you think your resiliency impacted your accessibility to education or that your education impacted your resiliency? How so?

6.) How did access to education empower you?

7.) What were some of biggest challenges for you?

8.) How do you think access to education impacted you and your community?

9.) Do you think there are certain characteristics that make successful students thrive?

10.) What do you think has allowed BIHE to survive in spite of oppression?

11.) Based on your experience, what message or insights would you want to other individuals who face systematic oppression to know?

12.) Following this interview, what supports to you have access to in your community?

13.) Is there anything else you would like me to know and if you had to say anything about your education and experience at BIHE. 


\section{Appendix B}

\section{Survey Questions}

Thank you for participating in "An exploration of how resilience combats oppression among minorities: A case study of the Baha'i underground university in Iran."

Please complete the following questions and email them to: kimiya.missaghi@carleton.ca

1.) What years did you attend the Baha'i Institute for Higher Education (BIHE)?

2.) What did you study at Baha'i Institute for Higher Education (BIHE)?

3.) Have you received further education?

3a.) If answered yes, what did you study and why did you study this particular subject?

3b.) If answered no, why did you not pursue further education?

4.) How do you define resiliency?

5.) Do you think you are a resilient person? Why or why not?

5a.) If you answered yes to question 5, do you think your education at the Baha'i Institute for Higher Education (BIHE) contributed to your resiliency? Why or Why not?

6.) Do you feel your education at BIHE has impacted your community? If yes, how so? If no, why not?

7.) What message would you want other individuals who have had similar experiences to know? 


\section{Appendix C}

\section{Oral Research Consent}

Hello, my name is Kimiya Missaghi and I am a master's student in the Department of Law and Legal Studies at Carleton University. I am working under the supervision of Professor Melanie Adrian.

I would like to invite you to participate in a study titled "An exploration of how resilience combats oppression among minorities: A case study of the Baha'i underground university in Iran." This study aims to learn more about resilience and education among alumnus from the Baha'i Institute of Higher Education.

The study involves an interview and a survey about your experiences and resiliency. With your consent the interview will be audio recorded and once transcribed, the recording will be destroyed. We estimate that the survey/interview will take about 2 hours to complete. Your participation in this survey is voluntary, and you may choose not to take part, or not to answer any of the questions. If you decide to withdraw after the interview, your responses will be removed if you notify the researcher by June 1st, 2020.

We will treat your personal information as confidential, although absolute privacy cannot be guaranteed. No information that discloses your identity will be released or published without your specific consent. However, research records identifying you may be inspected by the Carleton University Research Ethics Board for the purpose of monitoring the research. The results of this study may be published, but the data will be presented so that it will not be possible to identify any participants. All research data will be password protected] and any hard copies of data will be kept in a locked cabinet at Carleton University.

You will be assigned a code so that your identity will not be directly associated with the data you have provided. All data, including coded information, will be kept in a password-protected file on a secure computer. Your de-identified data will be retained for a period of two years and then securely destroyed.

This project was reviewed and cleared by the Carleton University Research Ethics Board. If you have any ethical concerns with the study, please contact the Carleton University Research Ethics Board by phone at 613-520-2600 ext. 2517 or by email at ethics@carleton.ca.

You can also reach me at—or email me at kimiya.missaghi@carleton.ca. You may contact my supervisor at melanie.adrian@carleton.ca.

\section{Statement of consent}

Do you have any questions about this study or need any clarification?

Do you voluntarily agree to participate in the study?

Do you agree to be audio recorded? Yes

Yes No

Date: No

Participant's Name/Pseudonym/Initials (as appropriate): 


\section{Research team member who interacted with the subject}

I have explained the study to the participant and answered any and all of their questions. The participant appeared to understand and agree. I provided a copy of the consent information to the participant for their reference.

Signature of researcher

Date 


\section{Appendix D}

\section{Research Consent for Survey}

\section{Name and contact information of researchers:}

Kimiya Missaghi

Carleton University

Department of Law and Legal Studies

Email:

Telephone:

Supervisor and Contact Information:

Dr. Melanie Adrian

Melanie.adrian@carleton.ca

\section{Project title:}

An exploration of how resilience combats oppression among minorities: A case study of the Baha'i underground university in Iran

Project sponsor and funder (if any)

None

\section{Carleton university project clearance}

Clearance \#: $112400 \quad$ Date of Clearance: April 1 ${ }^{\text {st }}, 2020$

\section{Invitation}

We are asking you to complete this survey because you are an alumnus from the Baha'i Institute of Higher Education. This survey is being conducted by Kimiya Missaghi at Carleton University at the Department of Law and Legal Studies working under the supervision of Professor Melanie Adrian.

\section{Objectives and Summary:}

The aim of this study is to better understand resiliency and education.

We estimate that the survey will take about 15 minutes to complete. Your participation in this survey is voluntary, and you may choose not to take part, or not to answer any of the questions. If you decide to withdraw after you submit the survey, we will remove your responses from survey data if you notify the researcher by June 1st, 2020.

\section{Risks and benefits:}

We do not anticipate any risks from taking the survey, nor do we anticipate that you will derive any benefit. 


\section{Confidentiality and data storage:}

We will treat your personal information as confidential, although absolute privacy cannot be guaranteed. No information that discloses your identity will be released or published without your specific consent. Research records may be accessed by the Carleton University Research Ethics Board in order to ensure continuing ethics compliance.

All data will be kept confidential, unless release is required by law (e.g. child abuse, harm to self or others). The results of this study may be published, but the data will be presented so that it will not be possible to identify you, unless you give consent. All research data will be passwordprotected and any hard copies of data will be kept in a locked cabinet at Carleton University. Your data will be retained for a period of two years and then securely destroyed.

\section{REB review and contact information:}

This project was reviewed and cleared by the Carleton University Research Ethics Board. If you have any ethical concerns with the study, please contact the Carleton University Research Ethics Board by phone at 613-520-2600 ext. 2517] or by email at ethics@carleton.ca.

\section{Implied consent:}

By completing and returning the survey, you agree to participate in the study.

\section{Direct consent:}

I voluntarily agree to participate in this study. 


\section{Appendix E}

\section{Informed Consent Form}

\section{Name and contact information of researchers:}

Kimiya Missaghi, Carleton University, Department of Law and Legal Studies, Faculty of Public Affairs

Tel.:

Email: kimiya.missaghi@carleton.ca

Supervisor and Contact Information:

Dr. Melanie Adrian

melanie.adrian@carleton.ca

\section{Project title}

An exploration of how resilience combats oppression among minorities: A case study of the Baha'i underground university in Iran

Project sponsor and funder (if any)

$N / A$

\section{Carleton university project clearance}

Clearance \#: $112400 \quad$ Date of Clearance: April $1^{\text {st }}, 2020$

\section{Invitation}

You are invited to take part in a research project because you are an alumnus from the Baha' $i$ Institute of Higher Education. The information in this form is intended to help you understand what we are asking of you so that you can decide whether you agree to participate in this study. Your participation in this study is voluntary, and a decision not to participate will not be used against you in any way. As you read this form, and decide whether to participate, please ask all the questions you might have, take whatever time you need, and consult with others as you wish.

\section{What is the purpose of the study?}

The Baha'i community in Iran has been subject to a systematic mix of violent persecution in the form of arbitrary jailing, torture and killing, economic deprivation and marginalization, and cultural and social stigmatization. The Baha'i Institute for Higher Education (BIHE), an underground university, was a response to the Iranian State's formal expulsion and exclusion of Baha'i students and scholars from Iranian universities. BIHE would be a case study in which I could potentially interview alumni to showcase the unique response to violence and the implications of a peacebuilding response to situations of threat. I am studying BIHE alumni to understand what a BIHE education has meant for them and how, when they reflect back on their education, they understand resiliency in the face of oppression. 


\section{What will you be asked to do?}

If you agree to take part in the study, we will ask you to:

Complete a brief survey in person or via email. If emailing the survey to the researcher, you have the option to send file as a password protected attachment

Complete an individual interview for approximately two hours either in person at a location that the researcher and participant agree to or online via Skype-to-Skype video or voice call

The interview will be audio recorded

The interview location will be at a mutually convenient location or via Skype-to-Skype voice or video call if it is not possible to meet in person due to geographical constraints

\section{Risks and inconveniences}

We do not anticipate any risks to participating in this study.

\section{Possible benefits}

Reflection on education is a benefit in and of itself and you, as a participant, may benefit from a wider conversation of your experiences.

\section{Compensation/Incentives}

You will not be paid or compensated for your participation in this study.

\section{No waiver of your rights}

By signing this form, you are not waiving any rights or releasing the researchers from any liability.

\section{Withdrawing from the study}

If you withdraw your consent during the course of the study, all information collected from you before your withdrawal will be discarded or will still be used, unless you request that it be removed from the study data.

If you withdraw your consent during the course of the study, all information collected from you before your withdrawal will be discarded from the study if before the data collection phase is completed. All data from the study will be anonymized.

After the study, you may request that your data be removed from the study and deleted by notice given to the Principal Investigator, Kimiya Missaghi before June 1st, 2020.

\section{Confidentiality}

We will remove all identifying information from the study data as soon as the interview is complete. You will be associated with a participant identification number and your name and personal identification will be removed and will not be discussed in the final thesis. 
We will treat your personal information as confidential, although absolute privacy cannot be guaranteed. No information that discloses your identity will be released or published without your specific consent. Research records may be accessed by the Carleton University Research Ethics Board in order to ensure continuing ethics compliance. All data will be kept confidential, unless release is required by law (e.g. child abuse, harm to self or others). The results of this study may be published or presented at an academic conference or meeting, but the data will be presented so that it will not be possible to identify any participants unless you give your express consent. You will be assigned a code [or pseudonym] so that your identity will not be directly associated with the data you have provided. All data, including coded information, will be kept in a password-protected [or encrypted] file on a secure computer. Your data will be stored and protected by Carleton University in two password protected external hard drives that will be kept secured in a locked room. Data may be disclosed via a court order.

We will password protect any research data that we store.

\section{Data retention}

Your de-identified data will be retained for a period of 2 years after the completion of analysis and then securely destroyed.

\section{New information during the study}

In the event that any changes could affect your decision to continue participating in this study, you will be promptly informed.

\section{Ethics review}

This project was reviewed and cleared by the Carleton University Research Ethics Board [A]. If you have any ethical concerns with the study, please contact Carleton University Research Ethics Board (by phone at 613-520-2600, ext. 2517 for CUREB A or by email at ethics@carleton.ca.

\section{Statement of consent - print and sign name}

I voluntarily agree to participate in this study.

I agree to be audio recorded

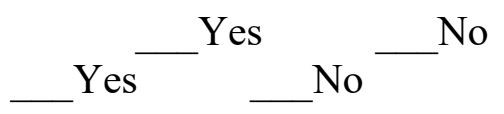

Signature of participant

Date

\section{Research team member who interacted with the subject}

I have explained the study to the participant and answered any and all of their questions. The participant appeared to understand and agree. I provided a copy of the consent form to the participant for their reference. 


\section{Appendix F}

\section{Email Letter of Introduction}

Subject: Invitation to participate in a research project on how resilience combats oppression among minorities, focusing on alumni from the Baha'i Institute of Higher Education (BIHE) in Iran

\section{Dear [insert community region here]}

My name is Kimiya Missaghi and I am a master's student in the Law and Legal Studies Department at Carleton University in Ottawa, Ontario. I am working on a research project under the supervision of Professor Melanie Adrian.

My study is entitled "An exploration of how resilience combats oppression among minorities: A case study of the Baha'i underground university in Iran".

I will be interviewing individuals living outside of Iran, who graduated from the Baha'i Institute of Higher Education (BIHE). I am writing to you to request if you could reach out to your community if there any potential participants that may be interested in participating. Interviews can take place in person or via Skype. I have attached a recruitment poster to this email for your convenience.

The study involves one 2-hour interview that will take place in a mutually convenient, safe location or online. With their consent, interviews will be audio-recorded. Once the recording has been transcribed, the audio-recording will be destroyed. While this project does involve some professional and emotional risks, care will be taken to protect their identity. This will be done by keeping all responses anonymous and allowing them to request that certain responses not be included in the final project.

They will have the right to end your participation in the study at any time, for any reason, up until June 1st, 2020. If they choose to withdraw, all the information you have provided will be destroyed. All research data, including audio-recordings and any notes will be encrypted. Any hard copies of data (including any handwritten notes or USB keys) will be kept in a locked cabinet at Carleton University. Research data will only be accessible by the researcher and the research supervisor.

If you have any questions, please contact me at kimiya.missaghi@,carleton.ca

Sincerely,

Kimiya Missaghi 


\section{Appendix G}

\section{Recruitment Poster}

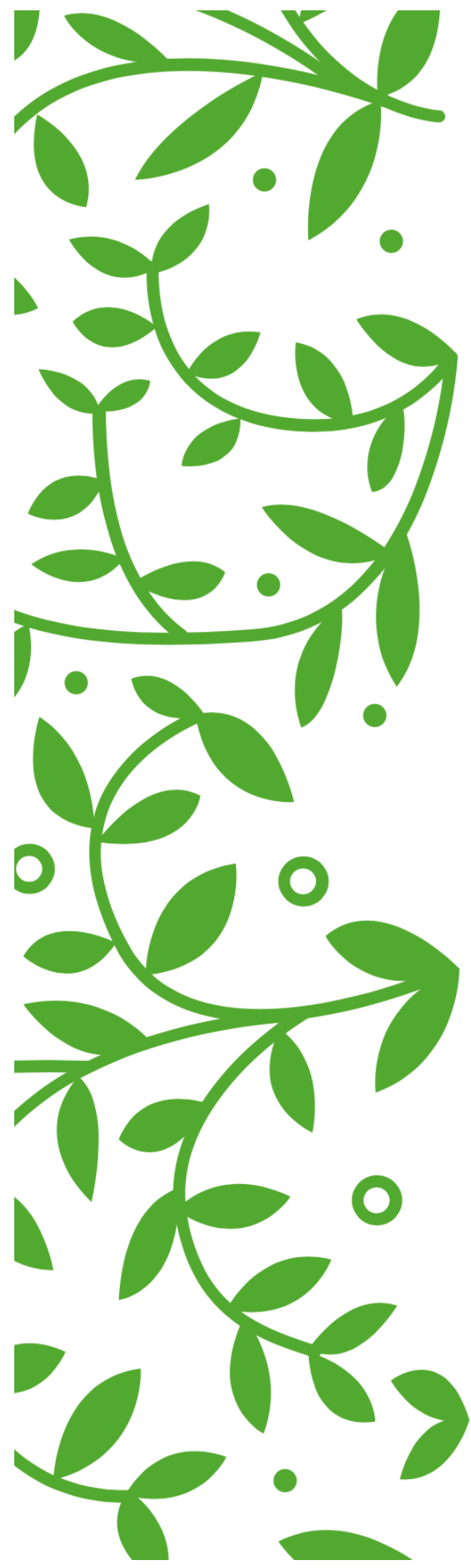

RECRUITING BIHE ALUMNI IN NORTH AMERICA

"An exploration of how resilience combats oppression among minorities: A case study of the Baha'i underground university in Iran"

Participants must be alumni from the Baha'i Institute of Higher Education and be living outside of Iran. Participants must speak English fluently. Participation in study requires two hours.

If interested in participating, please contact principle investigator, Kimiya Missaghi at kimiya.missaghi@carleton.ca

The ethics protocol for this project has been reviewed and cleared by the Carleton University Research Ethics Board. If you have any ethical concerns with the study, please contact the Carleton University Research Ethics Board-A by phone at 613-520-2600 ext. 2517 or via email at ethics@carleton.ca. 